\title{
A network pharmacology analysis on drug-like compounds from Ganoderma lucidum for alleviation of Atherosclerosis
}

Ki Kwang Oh

Kangwon National University

Md. Adnan

Kangwon National University

Dong Ha Cho ( $\sim$ chodh@kangwon.ac.kr)

Kangwon National University

\section{Research Article}

Keywords: Ganoderma lucidum, Atherosclerosis, Network Pharmacology, MAPK signaling pathway, PRKCA, Drug-like compounds

Posted Date: February 26th, 2021

DOI: https://doi.org/10.21203/rs.3.rs-236410/v1

License: (c) (i) This work is licensed under a Creative Commons Attribution 4.0 International License. Read Full License 


\section{Abstract}

Background: Ganoderma lucidum (GL) is known as a potent alleviator against chronic inflammatory disease like atherosclerosis (AS), but its critical bioactive compounds and their mechanisms against AS have not been unveiled. This research aimed to identify the key compounds(s) and mechanism(s) of GL against AS through network pharmacology.

Methods: The compounds from GL were identified by gas chromatography-mass spectrum (GC-MS), and SwissADME screened their physicochemical properties. Then, the gene(s) associated with the screened compound(s) or AS related genes were identified by public databases, and we selected the overlapping genes using a Venn diagram. The networks between overlapping genes and compounds were visualized, constructed, and analyzed by RStudio. Finally, we performed molecular docking test (MDT) to identify key gene(s), compound(s) on AutoDockVina.

Results: A total of 35 compounds in GL was detected via GC-MS, and 34 compounds (accepted by the Lipinski's rule) were selected as drug-like compounds (DLCs). A total of 34 compounds were connected to the number of 785 genes and 2,606 AS-related genes were identified by DisGeNET and Online Mendelian Inheritance in Man (OMIM). The final 98 overlapping genes were extracted between the compoundsgenes network and AS-related genes. On Kyoto Encyclopedia of Genes and Genomes (KEGG) pathway enrichment, the number of 27 signaling pathways were sorted out, and a hub signaling pathway (MAPK signaling pathway), a core gene (PRKCA), and a key compound (Benzamide, 4-acetyl-N-(2,6dimethylphenyl)) were selected among the 27 signaling pathways via MDT.

Conclusion: Overall, we found that the identified 3 DLCs from GL have potent anti-inflammatory efficacy, improving AS by inactivating the MAPK signaling pathway.

\section{Introduction}

Atherosclerosis (AS), a chronic inflammatory disease, can make artery narrow which causes thrombosis, calcification, and muscle weakness, leading to aneurismal dilation [1]. AS is a persistent inflammatory and immune system disorder, covering multiple cell types, including mast cells, smooth muscle cells, endothelial cells, T-cells, macrophages, and monocytes [2]. AS complications are as such: brain stroke, heart attack, kidney failure, erectile dysfunction, and legs peripheral vascular disease, indicating that crucial strategy for the alleviation of these symptoms might be anti-inflammation. [3, 4]. Currently, anti-AS drugs are categorized into statins (3-hydroxy-3-methylglutaryl coenzyme A reductase inhibitors that lower lipoproteins) and fibrates (peroxisome proliferator-activated receptor-a agonists that diminish triglycerides) increase the amount of high-density lipoprotein levels $[5,6]$. However, both statins and fibrates drugs have some adverse effects commonly: dyspepsia, nausea, flatulence, intestinal constipation and even neuromuscular degenerative disorder [7]. Therefore, research on drug discovery from alternative sources has received much attention. 
The natural product extracts are relatively safe, although some include unexpected adverse side effects such as headache, vomiting, dizziness, and constipation [8]. Also, medicinal herbal plants have been considered one of the most substantial therapeutics for alleviating and preventing congestive heart failure, including AS [9]. The medicinal mushrooms categorized into natural products also have diverse pharmacological effects, including antimicrobial, antitumor, anti-inflammatory, and antiatherogenic activities [10]. Among medicinal mushrooms, Ganoderma lucidum (GL) is used as a beneficial antiinflammatory agent and cardiovascular diseases therapy [11, 12]. Korean Herbal Pharmacopoeia noted that GL could be used to treat AS, where the dosage of $\mathrm{GL}$ can be taken to maximum $18 \mathrm{~g} / \mathrm{day}$. An animal test reported that GL has anti-atherogenic effect, demonstrated by reducing oxidative stress and inflammation [13]. In addition, the human monocytic cell line (THP-1) macrophage experiment indicated that GL diminished inducible nitric oxide synthase (iNOS) expression level, which led to alleviation of AS [14]. Besides, most studies reported that $\beta$-glucan polysaccharide isolated from GL revealed as a potent antioxidant against AS [15-17]. However, a clinical study for $\beta$-glucan polysaccharide efficacy on innate immune responses in humans ( 10 healthy male volunteers) showed that $\beta$-glucan polysaccharide was not detected in serum samples after receiving of $1000 \mathrm{mg}$ once daily for 7 days [18], which indicated low pharmacokinetic properties. Generally, ligands' cell permeability is reduced typically when the topological polar surface area (TPSA) exceeds $140 \AA^{2}$ [19]. As a result, we infer that the $\beta$-glucan is very soluble, and cannot be accepted as a potent molecule due to inappropriate drug-like properties (TPSA: $268.68 \AA^{2}$ or Lipinski's rule violation). Other drug-like compounds (DLCs) and mechanism(s) of GL against AS have not been established completely, which should be substantiated to treat AS effectively. Furthermore, natural product extracts have synergistic effects through the combination of some active compounds [20].

Hence, we performed compound-gene and gene-gene networks analysis of GL ethanolic extract via network pharmacology concept. Network pharmacology is a systematic analysis method to investigate synergistic efficacy and potential mechanism(s) of multiple molecules on system biology-based methodology $[21,22]$. This analysis provides a point of regulation between multi-signaling pathways and multi-molecule-gene-pathway regulation, hinting at new drug development for clinical trials [23]. It is an efficient method to understand the mechanism of actions on herbal medicines and decipher multiplemolecules in the bioprocess network [24]. Currently, network pharmacology is used to investigate new target genes and compounds' relationships, which is optimal to discover the therapeutic potentiality of natural products [25].

In this study, network pharmacology was utilized to investigate the network of compounds-target proteins-atherosclerosis from GL with a holistic perspective. In particular, we selected only DLCs through both GC-MS analysis and physicochemical properties prediction in in-silico. Then, target genes related to DLCs or AS were selected by public databases and identified overlapping genes between DLCs and AS were extracted. Thereby, compound(s)-gene(s)-signaling pathway(s) of GL on AS were identified by analyzing their interactions. Finally, key compound(s), key gene(s), and a hub signaling pathway of GL 
against AS were revealed via molecular docking test (MDT). The workflow diagram is exhibited in Figure 1.

\section{Materials And Methods}

\subsection{Plant preparation, extraction}

The dried and powdered GL $(50 \mathrm{~g})$ was soaked in $500 \mathrm{~mL}$ of $100 \%$ ethanol (Daejung, Korea). The extraction was carried out in a sealed bottle for 7 days and repeated 3 times at room temperature $\left(20 \sim 22^{\circ} \mathrm{C}\right)$. During extraction processing, the sample was shaken several times to increase the yield rate. The ethanol was evaporated using a vacuum evaporator (IKA-RV8, Japan). The evaporated sample was dried under a digital heating bath (IKA-HB10, Japan) at $40{ }^{\circ} \mathrm{C}$.

\subsection{GC-MS condition}

The analysis was carried out using GC-MS system (Agilent 7890A, 5975C Agilent Technologies Inc., Santa Rosa, CA, USA), is equipped with a DB- 5 capillary column $(30 \mathrm{~m} \times 0.25 \mathrm{~mm} \times 0.25 \mu \mathrm{m})$. Firstly, the GCMS instrument was maintained at a temperature of $100{ }^{\circ} \mathrm{C}$ for 2.1 minutes. The temperature rose to 300 ${ }^{\circ} \mathrm{C}$ at the rate of $25^{\circ} \mathrm{C} / \mathrm{min}$ and was maintained for 10 minutes at the end of this period. Injection port temperature and helium flow rate were maintained as $250^{\circ} \mathrm{C}$ and $1.5 \mathrm{ml} / \mathrm{min}$. The samples injected in split mode at 10:1 and the ionization voltage were $70 \mathrm{eV}$. MS scan range was set at 35-900 (m/z) and the fragmentation patterns of mass spectra compared in W8N05ST Library MS database. The relative peak area of each compound in the chromatogram was calculated on each compound percentage. ChemStation integrater algorithms used as the concept of integration [26].

\subsection{The detection of GL chemical compounds by GC-MS and identification of DLCs}

The chemical compounds detected from GL via GC-MS input into the PubChem (https://pubchem.ncbi.nlm.nih.gov/) to select Simplified Molecular Input Line Entry System (SMILES) format. The screen of "Drug-like" property is based on Lipinski's rule in SwissADME (http://www.swissadme.ch/).

\subsection{Target genes related to DLCs or AS}

Target genes associated with the DLCs (accepted by Lipinski's rule) were obtained via both public databases - Similarity Ensemble Approach (SEA) (http://sea.bkslab.org/) and SwissTargetPrediction (STP) (http://www.swisstargetprediction.ch/) with "Homo Sapiens" setting. The AS-targeted genes were identified by DisGeNET (https://www.disgenet.org/search) and OMIM (https://www.ncbi.nlm.nih.gov/omim). The overlapping genes between DLCs -target genes and AStargeted genes were visualized on the Venn diagram by InteractiVenn (http://www.interactivenn.net/). The gene(s)-gene(s) network is constructed by STRING (https://string-db.org/) analysis.

\subsection{Signaling pathways of AS - targeted overlapping genes from DLCs-targeted genes}


Based on rich factor, signaling pathways of AS- targeted overlapping genes were analyzed by RStudio. The targets genes associated with signaling pathways were identified by STRING and constructed a size map. Degree value of signaling pathways - target genes represents the edges numbers of signaling pathways on target genes in network. The greater degree of genes is the more essential genes for GL's mechanism of action on AS.

\subsection{Identification of a hub signaling pathway and key genes against AS}

There were 27 signaling pathways related to the occurrence and development of AS. Identification of a hub signaling pathway based on rich factor and key genes connected to a hub signaling pathway identified by STRING.

\subsection{Preparation for MDT of potential key compounds}

The potential key compounds were first converted into .sdf from PubChem followed by .pdb format using Pymol, and later, the potential key compounds were converted into .pdbqt format through Autodock [26].

\subsection{Preparation for MDT of target proteins}

Seven target proteins of AS i.e. HSPB1 (PDB ID: 4MJH), PDGFRB (PDB ID: 3MJG), PRKCB (PDB ID: 2I0E), PRKCA (PDB ID: 3IW4), MAPK14 (PDB ID: 1WBW), RELA (PDB ID: 2061), PLA2G4A (PDB ID: 1BCI) were selected on STRING via RCSB PDB (https://www.rcsb.org/). The proteins selected as .pdb format were converted into .pdbqt format via Autodock (http://autodock.scripps.edu/).

\subsection{Potential key compounds - target protein docking simulation setting}

The ligand molecules were docked with target proteins utilizing autodock 4 by setting-up 4 energy range and 8 exhaustiveness as default to obtain 10 different poses of ligand molecules [26]. The 2D binding interactions were identified through LigPlot+ v.2.2 (https://www.ebi.ac.uk/thorntonsrv/software/LigPlus/). After docking, a key compound of lowest binding energy was selected to visualize the ligand-protein interaction in Pymol.

\section{Results}

\subsection{Potential bioactive compounds from SB}

A total of 35 compounds in GL were identified by the GC-MS analysis (Figure 2), and the name of compounds, retention time, and peak area (\%) were enlisted in Table 1. All 35 compounds were checked and only 4,9a-Bis(acetyloxy)-3-[(acetyloxy)methyl]-4a, 7b-dihydroxy-1,1,6,8-tetramethyl-5-oxo1a,1b,4,4a,5,7a,7b,8,9,9a-decahydro-1H cyclopropa[3,4]benzo[1,2-E]azulen-9-yl acetate \# (PubChem ID: 538181 ) violated Lipinski's rule (Molecular Weight $\leq 500 \mathrm{~g} / \mathrm{mol}$; Moriguchi octanol-water partition coefficient $\leq 4.15$; Number of Nitrogen or Oxygen $\leq 10$; Number of $\mathrm{NH}$ or $\mathrm{OH} \leq 5$ ). Additionally, membrane permeability is typically restricted when topological polar surface area (TPSA) exceeds $140 \AA^{2}$ [19]. The 
number of 33 compounds out of 35 did not surpass $140 \AA^{2}$. Both Formic acid, (3,5-dinitrophenyl)amino-, [3-(ethoxycarbonyl)prop-2-yl] ester (PubChem ID: 552329) and 4,9a-Bis(acetyloxy)-3-

[(acetyloxy)methyl]-4a,7b-dihydroxy-1,1,6,8-tetramethyl-5-oxo 1a,1b,4,4a,5,7a,7b,8,9,9a-decahydro-1Hcyclopropa[3,4]benzo[1,2-E]azulen-9-yl acetate \# (PubChem ID: 538181) were not accepted within the border. This information was exhibited in Table 2.

\subsection{Overlapping genes between SEA and STP linked to 34 compounds}

Based on the SMILES, a total of 423 genes from SEA and 551 genes from STP connected to 34 compounds were extracted (Supplementary Table S1). Venn diagram showed that 189 genes were overlapping between the two public databases (Figure 3).

\subsection{Overlapping genes between 189 genes (SEA and STP overlapping genes) and AS-related genes}

A total of 2,606 genes associated with AS were selected by using DisGeNET and OMIM human gene databases (Supplementary Table S2). The Venn diagram shows that 98 overlapping genes was identified between 2,606 genes related to AS and the 189 overlapping genes (Figure 4-A) (Supplementary Table S3). The gene-gene network of the 189 overlapping genes was constructed by STRING, which indicated 98 nodes and 134 edges (Figure 4-B).

\subsection{Identification of a hub signaling pathway on a bubble plot}

The KEGG analysis indicated that a total of overlapping 98 genes was enriched 27 signaling pathways ( $p$ value < 0.05) (Figure 5) (Table 3). This analysis is for identifying the AS-related signaling pathways from the number of 98 genes. A hub signaling pathway (inactivation of MAPK signaling pathway) and connected to 7 key genes (HSPB1, PDGFRB, PRKCB, PRKCA, MAPK14, RELA, and PLA2G4A) against AS was identified on STRING analysis.

\subsection{Acquisition of core genes related to signaling pathways}

The number of 34 core genes obtained by KEGG pathway enrichment analysis and PRKCA manifested the highest degree (16), which was followed by PRKCB (15), MAPK14 (14), and RELA (14) (Figure 6), (Table 4). Accordingly, PRKCA was the uppermost gene of GL against AS.

\subsection{MDT of 7 genes and 15 compounds related to MAPK signaling pathway}

The number of 7 genes and 15 compounds associated with MAPK signaling pathway was identified by both SEA and STP databases (Figure-7A). Also, each 6 genes excluding PDGFRB gene was strongly related to MAPK signaling pathway (Figure-7b). The MDT was performed to evaluate the binding affinity energy of these 15 compounds against their related each gene, respectively. The MDT of A1-A2 on HSPB1 protein (PDB ID: 4MJH) was analyzed in the "Homo Sapiens" setting. According to the docking score, the priority of binding energy is given: A1>A2. The two binding energy of A1-HSPB1 and A2-HSPB1 revealed -8.8 and $-6.6 \mathrm{kcal} / \mathrm{mol}$, respectively. The Benzamide, 4-acetyl-N-(2,6-dimethylphenyl)- (PubChem ID: 
147129) (A1) had the strongest affinity on HSPB1. The MDT between B1-B2 and PDGFRB protein (PDB ID: $3 M J G$ ) in the "Homo sapiens" setting shown binding affinity of each ligand, and the order of the priority of binding energy is as follows: B1>B2. The two-binding energy of B1-PDGFRB and B2-PDGFRB revealed -8.2 and $-7.9 \mathrm{kcal} / \mathrm{mol}$, respectively. The 3-[4-Methoxyphenyl] quinolin-4-ol (PubChem ID: 279953) (B1) had the strongest affinity on PDGFRB. The MDT between C1-C3 and PRKCB protein (PDB ID: 2IOE) in the "Homo sapiens" setting exposed binding affinity of each ligand, and the order of the priority of binding energy is as follows: $\mathrm{C} 1>\mathrm{C} 3>\mathrm{C} 2$. The two-binding energy of C1-PRKCB, C2-PRKCB and C3-PRKCB exhibited -8.4, -6.2, and -7.2 kcal/mol, respectively. The 1, 2, 3, 4-Tetrahydro-9-methyl-6cyclohexyl-1-carbazolone (PubChem ID: 535444) (C1) had the strongest affinity on PRKCB. The MDT between D1-D11 and PRKCA protein (PDB ID: 3IW4) in the "Homo sapiens" setting shown binding affinity of each ligand, and the order of the priority of binding energy is as follows:

D1 >D2>D6>D4>D8>D10>D7>D11=D5>D9>D3. The eleven-binding energy of D1-PRKCA, D2-PRKCA, D3PRKCA, D4-PRKCA, D5-PRKCA, D6-PRKCA, D7-PRKCA, D8-PRKCA, D9-PRKCA, D10-PRKCA, and D11PRKCA revealed $-8.0,-7.9,-4.4,-6.4,-5.2,-6.7,-5.6,-6.3,-5.0,-6.3$, and $-5.2 \mathrm{kcal} / \mathrm{mol}$, respectively. The Benzamide, 4-acetyl-N-(2,6-dimethylphenyl)- (PubChem ID: 147129) (D1) had the strongest affinity on PRKCA (the uppermost gene) (Figure 8-A, B). KEGG pathway enrichment analysis showed that inhibition of PRKCA blocks phosphorylation of RafB associated with inflammation [27] (Figure 8-C, D). The MDT between E1-E5 and MAPK14 protein (PDB ID: 1WBW) in the "Homo sapiens" setting shown binding affinity of each ligand, and the order of the priority of binding energy is as follows: E1>E2>E5>E4>E3. The five-binding energy of E1-MAPK14, E2-MAPK14, E3-MAPK14, E4-MAPK14, and E5-MAPK14 revealed -7.4, $-6.2,-3.6,-4.2$ and $-4.8 \mathrm{kcal} / \mathrm{mol}$, respectively. The Benzamide, 4-acetyl-N-(2,6-dimethylphenyl)- (PubChem ID: 147129) (E1) had the strongest affinity on MAPK14. The MDT between F1-F2 and RELA protein (PDB ID: 2061) in the "Homo sapiens" setting shown binding affinity of each ligand, and the order of the priority of binding energy is as follows: F1>F2. The two-binding energy of F1-RELA and F2-RELA revealed -8.2 and $-4.0 \mathrm{kcal} / \mathrm{mol}$, respectively. Interestingly, the MDT of 5 compounds (G1-G5) on PLA2G4A has inactive affinity scores $\left(>-6.0 \mathrm{kcal}^{*} \mathrm{~mol}^{-1}\right)$, thereby we did not consider them as promising molecule candidates against AS. The threshold of AutoDock Vina program is regarded as active molecules (binding affinity value $<-6.0 \mathrm{kcal}^{*} \mathrm{~mol}^{-1}$ ) and inactive molecules (binding affinity value $>-6.0 \mathrm{kcal}^{*} \mathrm{~mol}^{-1}$ ) [28]. The information is enlisted in Table 5.

\subsection{Comparative MDT against positive controls on target proteins}

The comparative MDT was performed to evaluate affinity between the highest docking score ligands and positive controls. Each positive control of target protein is as follows. The MDT of HSP27 inhibitor J2 (PubChem ID: 135384973) on HSPB1 protein (PDB ID: 4MJH) was $-7.3 \mathrm{kcal} / \mathrm{mol}$, while Benzamide, 4acetyl-N-(2, 6-dimethylphenyl) - (PubChem ID: 147129) (A1) had -8.8 kcal/mol. The A1 was a stronger binding affinity than the positive control (HSP27 inhibitor J2). The MDT of Axitinib (PubChem ID: 6450551) on PDGFRB protein (PubChem ID: $3 \mathrm{MJG}$ ) was $-8.1 \mathrm{kcal} / \mathrm{mol}$, whereas the 3-[4Methoxyphenyl]quinolin-4-ol (PubChem ID: 279953) was $-8.2 \mathrm{kcal} / \mathrm{mol}$. The B1 exposed a stronger binding affinity than the positive control (Axitinib). The MDT of GO 6983 (PubChem ID: 
5280335) on PRKCB (PubChem ID:2I0E) was -7.5 kcal/mol, where the 1,2,3,4-Tetrahydro-9-methyl-6cyclohexyl-1-carbazolone (PubChem ID: 147129) (C3) was $-8.4 \mathrm{kcal} / \mathrm{mol}$. The C3 exhibited a stronger binding affinity than the positive control (GO 6983). The MDT of Sphingosine (PubChem ID: 3499) on PRKCA protein (PubChem ID: 3IW4) was $-5.5 \mathrm{kcal} / \mathrm{mol}$, while Benzamide, 4-acetyl-N-(2,6dimethylphenyl)- (PubChem ID: 147129) (D11) had -8.0 kcal/mol. The D11 manifested stronger binding affinity than the positive control (Sphingosine). The MDT of JX-401 (PubChem ID: 1126109) on MAPK14 protein (PubChem ID: 1WBW) was -6.9 kcal/mol, whereas Benzamide, 4-acetyl-N-(2,6dimethylphenyl)- (PubChem ID: 147129) (E1) was $-7.4 \mathrm{kcal} / \mathrm{mol}$. The E1 revealed a stronger binding affinity than the positive control (JX-401). The MDT of Curcumenol (PubChem ID: 167812) on RELA (PDB ID: 2061) was -7.9 kcal/mol, while the 3-[4-Methoxyphenyl]quinolin-4-ol (PubChem ID: 279953) (F2) was $-8.2 \mathrm{kcal} / \mathrm{mol}$. The binding affinity of F2 was stronger than the positive control (Curcumenol). Conversely, the MDT of Berberine (PubChem ID: 2353) on PLA2G4A (PDB ID: 1BCI) was $-6.6 \mathrm{kcal} / \mathrm{mol}$, whereas the Erucic acid (PubChem ID: 5281116) (G3) was $-4.6 \mathrm{kcal} / \mathrm{mol}$. The Berberine (PubChem ID: 2353) had stronger affinity than Erucic acid in GL. The information is enlisted in Table 6.

\section{Discussion}

DLCs-genes network indicated that the therapeutic efficacy of GL on AS was related to 98 genes. The KEGG pathway enrichment analysis indicated that the number of 34 genes among 98 genes was connected to 27 signaling pathways related to the progression of AS, and might be implicated as the mechanism of GL against AS. Thus, interrelations of the 27 signaling pathways are concisely discussed as follows. Prolactin signaling pathway: Prolactin modulated the inflammatory response level in atherosclerotic lesions and showed a high expression level of prolactin receptors in atherosclerotic patients [29]. It implies that prolactin might be highly expressed in AS. PPAR signaling pathway: PPARa, PPARY, and PPAR $\beta / \delta$ inhibited the atherogenic inflammation and interrupted the accumulation of cholesterol [30]. VEGF signaling pathway: Expression level of VEGF in AS was increased during the development of disease [31]. Fc epsilon RI signaling pathway: Fc epsilon stimulated macrophage cell and consecutively formed foam cell to aggravate AS lesions [32]. Adipocytokine signaling pathway:

Adipocytokine contributes to endothelial dysfunction, vascular inflammation, and plaque formation, all of which are lesions of AS [33]. AGE-RAGE signaling pathway in diabetic complications: AGE-RAGE in diabetes aggravated AS, and RAGE might be a therapeutic target in inflammatory responses in vascular disease [34]. Thyroid hormone signaling pathway: Both hyperthyroidism and hypothyroidism induce cardiovascular disease; moreover, hypothyroidism is related to AS [35]. Sphingolipid signaling pathway: The atherosclerotic lesions comprise many sphingolipids, and sphingolipid synthesis inhibition is a potential mechanism of action against AS [36]. GnRH signaling pathway: GnRH receptor was highly expressed in atherosclerotic plaque, associated with cytokine activation [37, 38]. IL-17 signaling pathway: IL-17 expression level increased in early atherosclerotic lesions, conversely, decreased in the advanced stage of AS [39]. B cell receptor signaling pathway: B cell components were involved in atherosclerotic development via antibody production, which led to the direct regulation of immune cells [40]. T cell 
receptor signaling pathway: Activated T cells translocated into atherosclerotic plaques and its activation was regarded as a marker to be indicated the atherosclerotic plaques [41, 42]. HIF-1 signaling pathway: HIF-1 had a significant role in developing AS by producing foam cells with cholesterol [43]. Calcium signaling pathway: Calcium signaling pathway influences cytokine production in vascular disease [44]. FoxO signaling pathway: FoxO deacetylation could aggravate the atherosclerotic plaque formation and lead to the inflammatory responses in vascular disease [45]. ErbB signaling pathway: ErbB signaling activation progresses inflammation in vascular disease, and its inhibition might be an important target to alleviate the atherosclerotic lesions [46]. Relaxin signaling pathway: Relaxin is a hormone that has an inhibitory agent to relieve the atherosclerotic-associated lesions [47]. Wnt signaling pathway: Activation of Wnt signaling pathway interrupts lipid accumulation, foam cell production, and further prevents AS [48]. Chemokine signaling pathway: Chemokines interrupt smooth muscle cell, and platelet activation to induce atherosclerotic processing [49]. Phospholipase D signaling pathway: Knock-out mice of Phospholipase $D$ enzyme consumed more food than control animals, which led to fatty acid overaccumulation in the body [50]. It implies that Phospholipase D enzyme facilitates the metabolic processing against AS. TNF signaling pathway: TNF p55 receptors blocked atherosclerotic lesion progression in the mouse [51]. It implicates that activation of TNF p55 receptors might inhibit AS development. Oxytocin signaling pathway: An animal study suggested that oxytocin treatment diminished the level of IL-6 over 6 hours and alleviated AS lesions in the thoracic aorta [52]. Ras signaling pathway: Ras is a signaling molecule involved in AS development and vascular inflammation [53]. Neutrophin signaling pathway: The neutrophin signaling pathway was connected to AS-related ocular complications [54]. AMPK signaling pathway: The activation of AMPK signaling pathway plays a vital role in development of AS and its inhibition might be a potential target against AS [55]. Rap1 signaling pathway: Rap1 has anti-inflammatory signaling to block the development of AS, conversely, the activation of Rap1 increases atherosclerotic plaque [56]. MAPK signaling pathway: The MAPK is involved directly in proinflammatory responses, oxidative stress, and cytokines abundant in AS lesions [57]. It supports that inhibition of MAPK might be to ameliorate atherosclerotic lesions. The number of 3 DLCs related to 6 (excluding PLA2G4A) out of 7 target genes of MAPK signaling pathway demonstrated higher affinity score than positive controls. Among 7 target genes, PRKCA gene plays significant roles in 16 signaling pathways out of 27 signaling pathways by MAPK signaling pathway. The Benzamide, 4-acetyl-

$\mathrm{N}$-(2, 6-dimethylphenyl)-(PubChem ID: 147129) showed the highest binding affinity with 3 genes (HSPB1, PRKCA, and MAPK14) out of 7 target genes on MAPK signaling pathway, suggesting multi-target synergistic efficacy against AS.

\section{Conclusion}

Our findings via network pharmacology analysis indicated that the number of 34 genes was defined as "core genes" and PRKCA gene had the highest degree value that interacted 16 out of 27 signaling pathways. Through MDT, Benzamide, 4-acetyl-N-(2,6-dimethylphenyl) (PubChem ID: 147129); manifested the highest affinity score on PRKCA gene. Furthermore, both 3-[4-Methoxyphenyl] quinolin-4-ol (PubChem ID: 279953) and 1,2,3,4-Tetrahydro-9-methyl-6-cyclohexyl-1-carbazolone (PubChem ID: 535444) exposed 
higher affinity score on target proteins than positive controls. We elucidate that significant druggable 3 compounds in GL might be used for the treatment of AS. Among the 3 druggable compounds, MDT revealed that Benzamide, 4-acetyl-N-(2,6-dimethylphenyl)- had the most substantial inhibitory effect on PRKCA gene in MAPK signaling pathway. To sum things up, based on the holistic viewpoints, we concluded that Benzamide, 4-acetyl-N-(2,6-dimethylphenyl) (PubChem ID: 147129) in GL is the most potent bioactive to alleviate inflammatory responses against AS by inactivating PRKCA gene (a key gene) followed by inhibiting MAPK signaling pathway (a hub signaling pathway) on KEGG pathway.

\section{Abbreviations}

AMPK: AMP activated protein kinase;

AS: Atherosclerosis;

GC-MS: Gas Chromatography- Mass Spectrum;

DLCs: Drug Like Compounds;

ErbB: Epidermal growth factor receptor;

Fox0: Forkhead box 0;

GL: Ganoderma lucidum;

GnRH: GoNadotropin Releasing Hormone;

HIF-1: Hypoxia Inducible Factor-1;

IL-17: Interleukin-17;

iNOS: inducible Nitric Oxide Synthase;

KEGG: Kyoto Encyclopedia of Genes and Genomes;

MAPK: Mitogen Activated Protein Kinase;

MDT: Molecular Docking Test;

OMIM: Online Mendelian Inheritance in Man;

PPAR: Peroxisome Proliferator-Activated Receptor;

PPARa: Peroxisome Proliferator-Activated Receptor Alpha;

PPARY: Peroxisome Proliferator-Activated Receptor Gamma; 
PPARß/ס: Peroxisome Proliferator-Activated Receptor Beta/Delta;

Rap1: Ras-related protein 1;

SEA: Similarity Ensemble Approach;

SMILES: Simplified Molecular Input Line Entry System;

STP: SwissTargetPrediction;

TNF: Tumor Necrosis Factor;

TPSA: Topological Polar Surface Area;

VEGF: Vascular endothelial growth factor

\section{Declarations}

\section{Availability of data and materials}

The raw data supporting the conclusions of this manuscript will be made available by the authors, without undue reservation, to any qualified researcher. The datasets generated and/or analysed during the current study are available in DisGeNET (https://www.disgenet.org/search) and OMIM (https://www.ncbi.nlm.nih.gov/omim).

\section{Ethics declarations}

Ethics approval and consent to participate

Not applicable for this submission.

Consent for publication

Not applicable for this submission.

Competing interests

The authors declare that they have no competing interests.

\section{Funding}

This research did not receive any specific grant from funding agencies in the public, commercial, or notfor-profit sectors.

\section{Author Contributions}


K.K.O. conducted the conceptualization, methodology, formal analysis, data curation, original draft writing. M.A. interpreted the results, reviewed, and edited the original draft. D.H.C. investigated, reviewed, and interpreted the results. All authors read, critically reviewed, and consented to the manuscript.

\section{Acknowledgements}

This research was acknowledged by the Department of Bio-Health Convergence, Kangwon National University, Chuncheon 24341, Republic of Korea.

\section{References}

1. Conti P, Shaik-Dasthagirisaeb Y. Atherosclerosis: A chronic inflammatory disease mediated by mast cells. Central European Journal of Immunology. 2015;40:380-6. doi:10.5114/ceji.2015.54603.

2. Spirig R, Tsui J, Shaw S. The emerging role of TLR and innate immunity in cardiovascular disease. Cardiology Research and Practice. 2012;1:11. doi:10.1155/2012/181394.

3. Mozaffarian D, Benjamin EJ, Go AS, Arnett DK, Blaha MJ, Cushman M, et al. Heart disease and stroke statistics-2015 update: A report from the American Heart Association. Circulation. 2015;131:e29-39.

4. Libby P. Inflammation in atherosclerosis. Nature. 2002;420:868-74. doi:10.1038/nature01323.

5. Rosenson RS. Statins in atherosclerosis: Lipid-lowering agents with antioxidant capabilities. Atherosclerosis. 2004;173:1-12. doi:10.1016/S0021-9150(03)00239-9.

6. Kim NH, Kim SG. Fibrates revisited: Potential role in cardiovascular risk reduction. Diabetes and Metabolism Journal. 2020;44:213-21. doi:10.4093/DMJ.2020.0001.

7. Siqueira Carvalho AA, Poti Lima ÜW, Valiente RA. Statin and fibrate associated myopathy: Study of eight patients. Arq Neuropsiquiatr. 2004;62 2 A:257-61. doi:10.1590/s0004-282×2004000200013.

8. Ekor M. The growing use of herbal medicines: Issues relating to adverse reactions and challenges in monitoring safety. Frontiers in Neurology. 2014;4 JAN. doi:10.3389/fphar.2013.00177.

9. Kim JY, Shim SH. Medicinal herbs effective against atherosclerosis: Classification according to mechanism of action. Biomolecules and Therapeutics. 2019;27:254-64. doi:10.4062/biomolther.2018.231.

10. Lindequist $U$, Niedermeyer THJ, Jülich WD. The pharmacological potential of mushrooms. Evidencebased Complementary and Alternative Medicine. 2005;2:285-99. doi:10.1093/ecam/neh107.

11. Cai Z, Wong CK, Dong J, Jiao D, Chu M, Leung PC, et al. Anti-inflammatory activities of Ganoderma lucidum (Lingzhi) and San-Miao-San supplements in MRL/lpr mice for the treatment of systemic lupus erythematosus. Chin Med. 2016;11:23. doi:10.1186/s13020-016-0093-x.

12. Shaito A, Thuan DTB, Phu HT, Nguyen THD, Hasan H, Halabi S, et al. Herbal Medicine for Cardiovascular Diseases: Efficacy, Mechanisms, and Safety. Frontiers in Pharmacology. 2020;11:1. doi:10.3389/fphar.2020.00422.

13. Hsu PL, Lin YC, Ni H, Mo FE. Ganoderma triterpenoids exert antiatherogenic effects in mice by alleviating disturbed flow-induced oxidative stress and inflammation. Oxid Med Cell Longev. 
2018;2018.

14. Woo CWH, Man RYK, Siow YL, Choy PC, Wan EWY, Lau CS, et al. Ganoderma lucidum inhibits inducible nitric oxide synthase expression in macrophages. Mol Cell Biochem. 2005;275:165-71. doi:10.1007/s11010-005-1352-9.

15. Sargowo D, Ovianti N, Susilowati E, Ubaidillah N, Widya Nugraha A, Vitriyaturrida, et al. The role of polysaccharide peptide of Ganoderma lucidum as a potent antioxidant against atherosclerosis in high risk and stable angina patients. Indian Heart J. 2018;70:608-14. doi:10.1016/j.ihj.2017.12.007.

16. Wu YS, Ho SY, Nan FH, Chen SN. Ganoderma lucidum beta 1,3/1,6 glucan as an immunomodulator in inflammation induced by a high-cholesterol diet. BMC Complement Altern Med. 2016;16. doi:10.1186/s12906-016-1476-3.

17. Hwang IW, Kim BM, Kim YC, Lee SH, Chung SK. Improvement in $\beta$-glucan extraction from Ganoderma lucidum with high-pressure steaming and enzymatic pre-treatment. Appl Biol Chem. 2018;61:23542. doi:10.1007/s13765-018-0350-z.

18. Leentjens J, Quintin J, Gerretsen J, Kox M, Pickkers P, Netea MG. The Effects of Orally Administered Beta-Glucan on Innate Immune Responses in Humans, a Randomized Open-Label Intervention PilotStudy. PLoS One. 2014;9:e108794. doi:10.1371/journal.pone.0108794.

19. Matsson P, Kihlberg J. How Big Is Too Big for Cell Permeability? Journal of Medicinal Chemistry. 2017;60:1662-4. doi:10.1021/acs.jmedchem.7b00237.

20. Caesar LK, Cech NB. Synergy and antagonism in natural product extracts: When $1+1$ does not equal 2. Natural Product Reports. 2019;36:869-88. doi:10.1039/c9np00011a.

21. Zhao H, Shan Y, Ma Z, Yu M, Gong B. A network pharmacology approach to explore active compounds and pharmacological mechanisms of epimedium for treatment of premature ovarian insufficiency. Drug Des Devel Ther. 2019;13:2997-3007. doi:10.2147/DDDT.S207823.

22. Zhang GB, Li QY, Chen QL, Su SB. Network pharmacology: A new approach for Chinese herbal medicine research. Evidence-based Complementary and Alternative Medicine. 2013;2013.

23. Hua-Ying W, Jing L, Yi-Zhi M, Zhi-Ying Y, Feng L, Liang L, et al. Network Pharmacology Approach to Investigate the Preventive Mechanism of Hunan Expert Group Recommended Chinese Medicine Prevention No. 2 Prescription Against COVID-19. Digit Chinese Med. 2020;3:116-32.

24. Liang X, Li H, Li S. A novel network pharmacology approach to analyse traditional herbal formulae: The Liu-Wei-Di-Huang pill as a case study. Mol Biosyst. 2014;10:1014-22. doi:10.1039/c3mb70507b.

25. Kibble M, Saarinen N, Tang J, Wennerberg K, Mäkelä S, Aittokallio T. Network pharmacology applications to map the unexplored target space and therapeutic potential of natural products. Nat Prod Rep. 2015;32:1249-66. doi:10.1039/c5np00005j.

26. Oh KK, Adnan M, Cho DH. Network pharmacology of bioactives from Sorghum bicolor with targets related to diabetes mellitus. PLoS One. 2020;15:e0240873. doi:10.1371/journal.pone.0240873.

27. Arnoux F, Lambert N, Fina F, Martin M, Kanaan S, Balandraud N, et al. A2.31 Braf ( $v$ raf murine sarcoma viral oncogene homologue B1) mutations in rheumatoid arthritis patients. Ann Rheum Dis. 
2015;74 Suppl 1:A28.2-A29. doi:10.1136/annrheumdis-2015-207259.66.

28. Shityakov S, Förster C. In silico predictive model to determine vector-mediated transport properties for the blood-brain barrier choline transporter. Adv Appl Bioinforma Chem. 2014;7:23-36. doi:10.2147/AABC.S63749.

29. Reuwer AQ, Twickler MTB, Hutten BA, Molema FW, Wareham NJ, Dallinga-Thie GM, et al. Prolactin levels and the risk of future coronary artery disease in apparently healthy men and women. Circ Cardiovasc Genet. 2009;2:389-95. doi:10.1161/CIRCGENETICS.109.853572.

30. Castrillo A, Tontonoz P. PPARs in atherosclerosis: The clot thickens. Journal of Clinical Investigation. 2004;114:1538-40. doi:10.1172/JCl23705.

31. Malecic N, Young HS. Excessive angiogenesis associated with psoriasis as a cause for cardiovascular ischaemia. Exp Dermatol. 2017;26:299-304. doi:10.1111/exd.13310.

32. Zhang X, Li J, Luo S, Wang M, Huang Q, Deng Z, et al. IgE contributes to atherosclerosis and obesity by affecting macrophage polarization, macrophage protein network, and foam cell formation. Arterioscler Thromb Vasc Biol. 2020;40:597-610. doi:10.1161/ATVBAHA.119.313744.

33. Zhang H. Emerging role of adipokines as mediators in atherosclerosis. World J Cardiol. 2010;2:370. doi:10.4330/wjc.v2.i11.370.

34. Jandeleit-Dahm K, Watson A, Soro-Paavonen A. The AGE/RAGE axis in diabetes-accelerated atherosclerosis. Clinical and Experimental Pharmacology and Physiology. 2008;35:329-34. doi:10.1111/j.1440-1681.2007.04875.x.

35. Ichiki T. Thyroid hormone and atherosclerosis. Vascular Pharmacology. 2010;52:151-6. doi:10.1016/j.vph.2009.09.004.

36. Manicke NE, Nefliu M, Chunping W, Woods JW, Reiser V, Hendrickson RC, et al. Imaging of lipids in atheroma by desorption electrospray ionization mass spectrometry. Anal Chem. 2009;81:8702-7.

37. Knutsson A, Hsiung S, Celik S, Rattik S, Mattisson IY, Wigren M, et al. Treatment with a GnRH receptor agonist, but not the $\mathrm{GnRH}$ receptor antagonist degarelix, induces atherosclerotic plaque instability in ApoE-/- mice. Sci Rep. 2016;6.

38. Wu S, Wolfe A. Signaling of cytokines is important in regulation of GnRH neurons. Molecular Neurobiology. 2012;45:119-25. doi:10.1007/s12035-011-8224-y.

39. Lu X. The Impact of IL-17 in Atherosclerosis. Curr Med Chem. 2017;24. doi:10.2174/0929867324666170419150614.

40. Sage AP, Mallat Z. Multiple potential roles for B cells in atherosclerosis. Ann Med. 2014;46:297-303. doi:10.3109/07853890.2014.900272.

41. Kritikou E, van der Heijden T, Swart M, van Duijn J, Slütter B, Wezel A, et al. Hypercholesterolemia Induces a Mast Cell-CD4 + T Cell Interaction in Atherosclerosis . J Immunol. 2019;202:1531-9. doi:10.4049/jimmunol.1800648.

42. Grivel JC, Ivanova O, Pinegina N, Blank PS, Shpektor A, Margolis LB, et al. Activation of T lymphocytes in atherosclerotic plaques. Arterioscler Thromb Vasc Biol. 2011;31:2929-37. 
doi:10.1161/ATVBAHA.111.237081.

43. Gao L, Chen Q, Zhou X, Fan L. The role of hypoxia-inducible factor 1 in atherosclerosis. Journal of Clinical Pathology. 2012;65:872-6. doi:10.1136/jclinpath-2012-200828.

44. Yuan Z, Miyoshi T, Bao Y, Sheehan JP, Matsumoto AH, Shi W. Microarray analysis of gene expression in mouse aorta reveals role of the calcium signaling pathway in control of atherosclerosis susceptibility. Am J Physiol - Hear Circ Physiol. 2009;296:H1336. doi:10.1152/ajpheart.01095.2008.

45. Qiang L, Tsuchiya K, Kim-Muller JY, Lin H V., Welch C, Accili D. Increased atherosclerosis and endothelial dysfunction in mice bearing constitutively deacetylated alleles of Foxo1 gene. J Biol Chem. 2012;287:13944-51. doi:10.1074/jbc.M111.332767.

46. Wang L, Huang Z, Huang W, Chen X, Shan P, Zhong P, et al. Inhibition of epidermal growth factor receptor attenuates atherosclerosis via decreasing inflammation and oxidative stress. Sci Rep. 2017;8. doi:10.1038/srep45917.

47. $\mathrm{Ng} \mathrm{HH}$, Leo CH, Parry LJ, Ritchie RH. Relaxin as a therapeutic target for the cardiovascular complications of diabetes. Frontiers in Pharmacology. 2018;9 MAY. doi:10.3389/fphar.2018.00501.

48. Boucher P, Matz RL, Terrand J. Atherosclerosis: Gone with the Wnt? Atherosclerosis. 2020;301:1522. doi:10.1016/j.atherosclerosis.2020.03.024.

49. Mach F. The role of chemokines in atherosclerosis. Current atherosclerosis reports. 2001;3:243-51. doi:10.1007/s11883-001-0067-y.

50. Viera JT, El-Merahbi R, Nieswandt B, Stegner D, Sumara G. Phospholipases D1 and D2 Suppress Appetite and Protect against Overweight. PLoS One. 2016;11. doi:10.1371/journal.pone.0157607.

51. Schreyer SA, Peschon JJ, LeBoeuf RC. Accelerated atherosclerosis in mice lacking tumor necrosis factor receptor p55. J Biol Chem. 1996;271:26174-8. doi:10.1074/jbc.271.42.26174.

52. Nation DA, Szeto A, Mendez AJ, Brooks LG, Zaias J, Herderick EE, et al. Oxytocin attenuates atherosclerosis and adipose tissue inflammation in socially isolated ApoE-/- Mice. Psychosom Med. 2010;72:376-82. doi:10.1097/PSY.0b013e3181d74c48.

53. Minamino T, Yoshida T, Tateno K, Miyauchi H, Zou Y, Toko H, et al. Ras Induces Vascular Smooth Muscle Cell Senescence and Inflammation in Human Atherosclerosis. Circulation. 2003;108:2264-9. doi:10.1161/01.CIR.0000093274.82929.22.

54. Gupta A, Mohanty P, Bhatnagar S. Integrative analysis of ocular complications in atherosclerosis unveils pathway convergence and crosstalk. J Recept Signal Transduct. 2015;35:149-64. doi:10.3109/10799893.2014.942462.

55. Ou T, Hou X, Guan S, Dai J, Han W, Li R, et al. Targeting AMPK signalling pathway with natural medicines for atherosclerosis therapy: an integration of in silico screening and in vitro assay. Nat Prod Res. 2016;30:1240-7. doi:10.1080/14786419.2015.1050672.

56. Singh B, Kosuru R, Lakshmikanthan S, Sorci-Thomas M, Zhang D, Sparapani R, et al. Endothelial Rap1 (Ras-Association Proximate 1) Restricts Inflammatory Signaling to Protect From the Progression of Atherosclerosis. Arterioscler Thromb Vasc Biol. 2020. 
57. Reustle A, Torzewski M. Role of p38 MAPK in atherosclerosis and aortic valve sclerosis. International Journal of Molecular Sciences. 2018;19. doi:10.3390/ijms19123761.

\section{Tables}

Table 1. A list of the identified 35 compounds from GL through GC-MS. 


\begin{tabular}{|c|c|c|c|c|}
\hline \multirow[b]{2}{*}{ No. } & \multirow[b]{2}{*}{ Compounds } & \multicolumn{2}{|l|}{ Pubchem } & \multirow{2}{*}{$\begin{array}{r}\text { Area } \\
(\%)\end{array}$} \\
\hline & & ID & $\mathrm{RT}$ (mins) & \\
\hline 1 & N-Butyl-N-cyclopentylamine & 13926513 & 3.808 & 0.39 \\
\hline 2 & Cycloheptane & 9265 & 3.885 & 0.44 \\
\hline 3 & 3-Methyl-5-hydroxy-isoxazole & 153000 & 6.087 & 0.2 \\
\hline 4 & Butyl isobutyrate & 7353 & 6.212 & 0.18 \\
\hline 5 & 2-Methyl-5-nitroimidazole & 12760 & 7.039 & 0.14 \\
\hline 6 & Ethyl butyrate & 7762 & 7.317 & 0.43 \\
\hline 7 & Nonylamine & 16215 & 7.481 & 0.53 \\
\hline 8 & 3,4-Trimethyl-5-pyrazolone & 76665 & 8.087 & 0.17 \\
\hline 9 & Stearic acid & 5281 & 8.510 & 0.9 \\
\hline 10 & Methyl dihydrohydnocarpate & 535041 & 8.750 & 0.51 \\
\hline 11 & Palmitic acid & 985 & $\begin{array}{r}8.942 \\
9.000 \\
9.058\end{array}$ & 5.34 \\
\hline 12 & Oleic Acid & 445639 & 9.423 & 1.33 \\
\hline 13 & Linoleic acid & 5280450 & 9.635 & 11.04 \\
\hline 14 & Methyl stearolate & 534587 & 9.808 & 1.22 \\
\hline 15 & 7,11-Hexadecadienal & 5364460 & $\begin{array}{r}9.914 \\
10.077\end{array}$ & 2.03 \\
\hline 16 & 9-Octadecenal & 5283381 & 10.000 & 1.23 \\
\hline 17 & Z-4-Nonadecen-1-ol acetate & 5363395 & 10.154 & 1.14 \\
\hline 18 & 1,1-Dicyclohexyltetradecane & 291313 & 10.317 & 2.3 \\
\hline 19 & Erucic acid & 5281116 & 10.414 & 1.15 \\
\hline 20 & $\begin{array}{l}\text { 4,9a-Bis(acetyloxy)-3-[(acetyloxy)methyl]-4a,7b-dihydroxy-1,1,6,8-tetramethyl-5-oxo- } \\
\text { 1a,1b,4,4a,5,7a,7b, 8,9,9a-decahydro-1H-cyclopropa[3,4]benzo[1,2-E]azulen-9-yl acetate \# }\end{array}$ & 538181 & 11.077 & 1.2 \\
\hline 21 & Benzamide, 4-acetyl-N-(2,6-dimethylphenyl)- & 1506504 & 11.433 & 1.16 \\
\hline 22 & 1,5-Dicyclopentyl-3-(2-cyclopentylethyl)pentane & 281840 & 12.221 & 0.98 \\
\hline 23 & 2-Chlor-4-bromacetanilid & 610167 & 13.260 & 0.78 \\
\hline 24 & 3-[4-Methoxyphenyl]quinolin-4-ol & 279953 & 13.500 & 3.08 \\
\hline 25 & 9(11)-Dehydroergosteryl benzoate & 5366124 & 13.615 & 0.87 \\
\hline 26 & 2,4,6-Triisopropylbenzoic acid & 96214 & 13.808 & 1.67 \\
\hline 27 & 6-Chloro-2,3,7-trimethyl-5-nitroquinoxaline & 10106220 & 15.240 & 1.46 \\
\hline 28 & Hexanoic acid, 4-[(1-oxohexyl)amino]phenyl ester & 538937 & 15.317 & 1.28 \\
\hline 29 & 5,8,22-Ergostatrienol & 91743901 & 15.750 & 38.16 \\
\hline 30 & 5,6-Dihydroergosterol & 91691444 & 15.933 & 6.38 \\
\hline 31 & 1,2,3,4-Tetrahy dro-9-methyl-6-cyclohexyl-1-carbazolone & 535444 & 16.385 & 0.31 \\
\hline 32 & Campesterol & 6428659 & 16.663 & 1.76 \\
\hline 33 & Pyridine-3-carboxamide, oxime, N-(2-trifluoromethylphenyl)- & 550559 & 17.029 & 0.54 \\
\hline 34 & Formic acid, (3,5-dinitrophenyl)amino-, [3-(ethoxycarbonyl)prop-2-yl] ester & 552329 & 20.452 & 0.37 \\
\hline 35 & 1,5-Dicyclopentyl-3-(2-cyclopentylethyl)pentane & 281840 & 22.750 & 0.97 \\
\hline
\end{tabular}

Table 2. Physicochemical properties of the 35 compounds for good oral bioavailability. 


\begin{tabular}{|c|c|c|c|c|c|c|c|c|}
\hline & \multirow[t]{4}{*}{ Compounds } & \multicolumn{4}{|c|}{ Lipinski Rules } & \multirow{3}{*}{$\begin{array}{l}\text { Lipinski's } \\
\text { Violations }\end{array}$} & \multirow{3}{*}{$\begin{array}{l}\text { Bioavailability } \\
\text { Score }\end{array}$} & \multirow{4}{*}{$\begin{array}{l}\text { TPSA } \\
(\AA \square)\end{array}$} \\
\hline & & \multirow[b]{2}{*}{ MW } & \multirow[b]{2}{*}{ HBA } & \multirow[b]{2}{*}{ HBD } & \multirow{2}{*}{$\begin{array}{l}\text { MLog } \\
P\end{array}$} & & & \\
\hline & & & & & & & & \\
\hline No. & & $<500$ & $<10$ & $\leq 5$ & $\leq 4.15$ & $\leq 1$ & $>0.1$ & \\
\hline 1 & N-Butyl-N-cyclopentylamine hydroch loride & 177.71 & 1 & 1 & 2.45 & 0 & 0.55 & 12.03 \\
\hline 2 & Cycloheptane & 98.19 & 0 & 0 & 3.48 & 0 & 0.55 & 0.00 \\
\hline 4 & Butyl isobutyrate & 144.21 & 2 & 0 & 1.96 & 0 & 0.55 & 26.30 \\
\hline 5 & 2-Methyl-5-nitroimidazole & 127.1 & 3 & 1 & -0.76 & 0 & 0.55 & 74.50 \\
\hline 6 & Ethyl butyrate & 116.16 & 2 & 0 & 1.27 & 0 & 0.55 & 26.30 \\
\hline 7 & Nonylamine & 143.27 & 1 & 1 & 2.54 & 0 & 0.55 & 26.02 \\
\hline 8 & 3,4-Trimethyl-5-pyrazolone & 126.16 & 2 & 1 & 0.3 & 0 & 0.55 & 41.46 \\
\hline 9 & Stearic acid & 284.48 & 2 & 1 & 4.67 & 1 & 0.85 & 37.30 \\
\hline 10 & Methyl dihydrohydnocarpate & 268.43 & 2 & 0 & 4.04 & 0 & 0.55 & 26.30 \\
\hline 12 & Oleic Acid & 282.46 & 2 & 1 & 4.57 & 1 & 0.85 & 37.30 \\
\hline 13 & Linoleic acid & 280.45 & 2 & 1 & 4.47 & 1 & 0.85 & 37.30 \\
\hline 14 & Methyl stearolate & 294.47 & 2 & 0 & 4.8 & 1 & 0.55 & 26.30 \\
\hline 15 & 7,11-Hexadecadienal & 236.39 & 1 & 0 & 4.1 & 0 & 0.55 & 17.07 \\
\hline 16 & 9-Octadecenal & 266.46 & 1 & 0 & 4.68 & 1 & 0.55 & 17.07 \\
\hline 17 & Z-4-Nonadecen-1-ol acetate & 324.54 & 2 & 0 & 5.25 & 1 & 0.55 & 26.30 \\
\hline 18 & 1,1-Dicyclohexyltetradecane & 362.68 & 0 & 0 & 8.27 & 1 & 0.55 & 0.00 \\
\hline 19 & Erucic acid & 338.57 & 2 & 1 & 5.47 & 1 & 0.85 & 37.30 \\
\hline 20 & $\begin{array}{l}\text { 4,9a-Bis (acetyloxy)-3-[(acetyloxy)methyl]-4a,7b-dihydroxy-1,1,6,8-tetramethyl-5-oxo-1a, 1b,4,4a,5,7a,7b,8,9,9a- } \\
\text { decahydro-1H-cyclopropa[3,4] benzo[1,2-E]azulen-9-yl acetate \# }\end{array}$ & 548.58 & 11 & 2 & 1.04 & 2 & 0.17 & 162.73 \\
\hline 21 & Benzamide, 4-acetyl-N-(2,6-dimethylphenyl)- & 267.32 & 2 & 1 & 3.07 & 0 & 0.55 & 46.17 \\
\hline 22 & 1,5-Dicyclopentyl-3-(2-cyclopentylethyl)pentane & 304.55 & 0 & 0 & 7.43 & 1 & 0.55 & 0.00 \\
\hline 23 & 2-Chlor-4-brom acetanilid & 248.5 & 2 & 1 & 2.83 & 0 & 0.55 & 29.10 \\
\hline 24 & 3-[4-Methoxyphenyl]quinolin-4-ol & 251.28 & 2 & 1 & 1.91 & 0 & 0.55 & 42.09 \\
\hline 27 & 6-Chloro-2,3,7-trimethyl-5-nitroquinoxaline & 251.67 & 4 & 0 & 1.24 & 0 & 0.55 & 71.60 \\
\hline 28 & Hexanoic acid, 4-[(1-oxohexyl)amino]phenyl ester & 305.41 & 3 & 1 & 3.5 & 0 & 0.55 & 55.40 \\
\hline 29 & 5,8,22-Ergostatrienol & 396.65 & 1 & 1 & 6.33 & 1 & 0.55 & 20.23 \\
\hline 30 & 5,6-Dihydroergosterol & 398.66 & 1 & 1 & 6.43 & 1 & 0.55 & 20.23 \\
\hline 31 & 1,2,3,4-Tetrahydro-9-methyl-6-cyclohexyl-1-carbazolone & 281.39 & 1 & 0 & 3.51 & 0 & 0.55 & 22.00 \\
\hline 32 & Campesterol & 400.68 & 1 & 1 & 6.54 & 1 & 0.55 & 20.23 \\
\hline 33 & Pyridine-3-carboxamide, oxime, N-(2-triflu orom ethylphenyl)- & 281.23 & 6 & 2 & 2.77 & 0 & 0.55 & 57.51 \\
\hline 34 & Formic acid, (3,5-dinitrophenyl)amino-, [3-(ethoxycarbonyl)prop-2-yl] ester & 341.27 & 8 & 1 & 0.2 & 1 & 0.55 & 156.27 \\
\hline 35 & 1,5-Dicyclopentyl-3-(2-cyclopentylethyl)pentane & 304.55 & 0 & 0 & 7.43 & 1 & 0.55 & 0.00 \\
\hline
\end{tabular}

MW, Molecular Weight (g/mol); HBA, Hydrogen Bond Acceptor; HBD, Hydrogen Bond Donor; LogP, Lipophilicity; Bioavailability Score, The ability of a drug or other substance to be absorbed and used by the body; TPSA, Topological Polar Surface Area

Table 3. Target genes in 27 signaling pathways enrichment related to AS. 


\begin{tabular}{|c|c|c|}
\hline KEGG ID & Target genes & False discovery rate \\
\hline hsa04917: Prolactin signaling pathway & ESR1,ESR2,STAT3, MAPK1,RELA, MMP9,CYP17A1 & 0.00000348 \\
\hline hsa03320:PPAR signaling pathway & PPARD, RXRA, NR1H3,PPARG, PPARA, FABP4,FABP3 & 0.00000358 \\
\hline has04370:VEGF signaling pathway & HSPB1,PLA2G4A, MAPK1,PRKCA, PRKCB & 0.00018 \\
\hline hsa04664:Fc epsilon RI signaling pathway & PLA2G4A, MAPK1,PRKCA,ALOX5,FYN & 0.00027 \\
\hline hsa04920:Adipocytokine signaling pathway & PRKAB1, RXRA, STAT3, RELA, PPARA & 0.00029 \\
\hline hsa04933:AGE-RAGE signaling pathway in diabetic complications & RELA, MAPK1, STAT3, PRKCA, PRKCB,PRKCE & 0.00017 \\
\hline hsa04919:Thyroid hormone signaling pathway & ESR1,HDAC1,RXRA, HDAC3, MMP9, PRKCA, PRKCB & 0.0000443 \\
\hline hsa04071:Sphingolipid signaling pathway & RELA, MAPK1,PRKCA,PRKCB, FYN,PRKCE, S1PR1 & 0.0000443 \\
\hline hsa04912:GnRH signaling pathway & PLA2G4A, MAPK1,PRKCA,PRKCB & 0.005 \\
\hline hsa04657:IL-17 signaling pathway & MAPK1,RELA, GSK3B, MMP9 & 0.0056 \\
\hline hsa04662:B cell receptor signaling pathway & PRKCB, RELA, GSK3B & 0.0159 \\
\hline hsa04660:T cell receptor signaling pathway & MAPK1, RELA, GSK3B, FYN & 0.0065 \\
\hline hsa04066:HIF-1 signaling pathway & STAT3, RELA, PRKCA, PRKCB & 0.0065 \\
\hline hsa04020:Calcium signaling pathway & PRKCA, PRKCB, PDGFRB, TBXA2R,HRH1,PTGER3 & 0.00033 \\
\hline hsa04068:FoxO signaling pathway & SETD7,STAT3, MAPK1,S1PR1,PRKAB1 & 0.003 \\
\hline hsa04012:ErbB signaling pathway & PRKCA, PRKCB, GSK3B & 0.0211 \\
\hline hsa04926: Relaxin signaling pathway & MAPK1,PRKCA, RELA, MMP9 & 0.0132 \\
\hline hsa04310:Wnt signaling pathway & PRKCA, PRKCB, GSK3B, PPARD & 0.016 \\
\hline hsa04062:Chemokine signaling pathway & STAT3, PRKCB, RELA, GSK3B, CCR9 & 0.0081 \\
\hline hsa04072:Phospholipase D signaling pathway & PLA2G4A,PRKCA,FYN,PDGFRB & 0.0164 \\
\hline hsa04668:TNF signaling pathway & MAPK1, RELA, MMP9 & 0.0365 \\
\hline hsa04921:Oxytocin signaling pathway & PRKAB1,PLA2G4A,PRKCA,PRKCB & 0.0175 \\
\hline hsa04014:Ras signaling pathway & PLA2G2A, PLA2G4A, RELA, PRKCA, PRKCB,PDGFRB & 0.0049 \\
\hline hsa04722:Neurotrophin signaling pathway & MAPK1,RELA, GSK3B & 0.0421 \\
\hline hsa04152:AMPK signaling pathway & PRKAB1,HMGCR,PPARG & 0.0455 \\
\hline hsa04015:Rap1 signaling pathway & CNR1, MAPK1,PRKCA, PRKCB,PDGFRB & 0.012 \\
\hline hsa04010:MAPK signaling pathway & HSPB1, PLA2G4A, MAPK1, RELA, PRKCA, PRKCB,PDGFRB & 0.0037 \\
\hline
\end{tabular}

Table 4. Degree values of target genes.

No. Gene symbol Degree No. Gene symbol Degree

\begin{tabular}{rlccll}
\hline \hline 1 & PRKCA & 16 & 18 & PRKCE & 2 \\
2 & PRKCB & 15 & 19 & S1PR1 & 2 \\
3 & MAPK14 & 14 & 20 & ALOX5 & 1 \\
4 & RELA & 14 & 21 & CCR9 & 1 \\
5 & GSK3B & 7 & 22 & CNR1 & 1 \\
\hline 6 & PLA2G4A & 7 & 23 & CYP17A1 & 1 \\
7 & STAT3 & 6 & 24 & ESR2 & 1 \\
8 & MMP9 & 5 & 25 & FABP3 & 1 \\
9 & PDGFRB & 5 & 26 & FABP4 & 1 \\
\hline 10 & FYN & 4 & 27 & HDAC1 & 1 \\
\hline 11 & PRKAB1 & 4 & 28 & HDAC3 & 1 \\
\hline 12 & RXRA & 3 & 29 & HRH1 & 1 \\
\hline 13 & ESR1 & 2 & 30 & NR1H3 & 1 \\
\hline 14 & HSPB1 & 2 & 31 & PTGER3 & 1 \\
\hline 15 & PPARA & 2 & 32 & SETD7 & 1 \\
\hline 16 & PPARD & 2 & 33 & TBXA2R & 1 \\
\hline 17 & PPARG & 2 & 34 & PLA2G2A & 1 \\
\hline
\end{tabular}


Table 5. Binding energy of potential active compounds from GL on MAPK signaling pathway.

*: The highest affinity molecule on a target protein 


\begin{tabular}{|c|c|c|c|c|c|c|}
\hline Protein & Ligand & Symbol & Pubchem ID & Binding energy $(\mathrm{kcal} / \mathrm{mol})$ & $\begin{array}{c}\text { Hydrogen bond interactions } \\
\text { Amino acid Residue }\end{array}$ & $\begin{array}{c}\text { Hydrophobic interactions } \\
\text { Amino acid residue }\end{array}$ \\
\hline \multirow[t]{6}{*}{ HSPB1 (PDB ID:4MJH) } & *Benzamide, 4-acetyl-N-(2,6-dimethylphenyl)- & A1 & 147129 & -8.8 & Arg140 & Phe138,Phe104,Asp100, \\
\hline & & & & & & Phe138,Leu99,Ile134, \\
\hline & & & & & & Arg136,His 103 \\
\hline & 7,11-Hexadecadienal & A2 & 5364460 & -6.6 & Arg140,Arg136 & Ile134,Cys137,Asp100, \\
\hline & & & & & & Phe138,Phe104,Arg136, \\
\hline & & & & & & Phe104,Phe138 \\
\hline \multirow[t]{7}{*}{ PDGFRB (PDB ID:3MJG) } & *3-[4-Methoxyphenyl]quinolin-4-ol & B1 & 279953 & -8.2 & N/A & Ile13,Tyr205,Cys 16 \\
\hline & & & & & & Glu 15,Lys 164,Lys98 \\
\hline & & & & & & Cys97,Cys99,Ser187 \\
\hline & & & & & & Asn54 \\
\hline & Benzamide, 4-acetyl-N-(2,6-dim ethylphenyl)- & B2 & 147129 & -7.9 & Lys164,Asn 54 & Cys 97, Lys 98,Glu 162 \\
\hline & & & & & & Arg186, Ile13,Tyr205 \\
\hline & & & & & & Ser187,Glu 15,Cys 16 \\
\hline \multirow[t]{10}{*}{ PRKCB (PDB ID: 2IOE) } & *1,2,3,4-Tetrahydro-9-methyl-6-cyclohexyl-1-carbazolone & $\mathrm{C} 1$ & 535444 & -8.4 & Gly495,Ser664 & Glu665,Phe661,Arg392 \\
\hline & & & & & & Lys 391,Ala395,Val496 \\
\hline & & & & & & Pro397 \\
\hline & Hexanoic acid, 4-[(1-oxohexyl)amino]phenyl ester & $\mathrm{C} 2$ & 538937 & -6.2 & Lys 520,Ser521 & Ile492,Gly519,Asp494 \\
\hline & & & & & & Tyr518,Gly495,Pro517 \\
\hline & & & & & & Gln516,Glu511,Pro580 \\
\hline & & & & & & Gly581,Cys 586,Trp493 \\
\hline & 3-[4-Methoxyphenyl]quinolin-4-ol & C3 & 279953 & -7.2 & Arg392 & Val496,Ala395,Lys391 \\
\hline & & & & & & Met388,Thr497,Gly495 \\
\hline & & & & & & Phe661 \\
\hline \multirow[t]{14}{*}{ PRKCA (PDB ID: 3IW4) } & *Benzamide, 4-acetyl-N-(2,6-dimethylphenyl)- & D1 & 1506504 & -8.0 & Gln 662 & Lys396,Asp395,Asn 660 \\
\hline & & & & & & Glu 552,Ser549,His553 \\
\hline & & & & & & Gln402,Leu393 \\
\hline & [4-Methoxyphenyl]quinolin-4-ol & D2 & 279953 & -7.9 & Asp649 & Asp373,Asn647,Ile648 \\
\hline & & & & & & Ser349,Phe350,Asp481 \\
\hline & & & & & & Lys 465,Ile376,Asp467 \\
\hline & 9-Octadecenal & D3 & 5283381 & -4.4 & $\mathrm{~N} / \mathrm{A}$ & Pro398,Glu552,Pro397 \\
\hline & & & & & & Lys396,Gln602,Asn 660 \\
\hline & & & & & & Asp395,Gln 402 \\
\hline & Erucic acid & D4 & 5281116 & -6.4 & Lys 396,Asp395,Asn 660 & Leu394,pro398,Arg608 \\
\hline & & & & & Leu393 & Lys478,His 665,Ile667 \\
\hline & & & & & & Tyr419,Pro666,Val664 \\
\hline & & & & & & $G \ln 402$ \\
\hline & Oleic Acid & D5 & 445639 & -5.2 & Leu393,Lys396 & Asn660,Gln402,Pro397 \\
\hline
\end{tabular}

Page 21/30 


\begin{tabular}{|c|c|c|c|c|c|}
\hline Lin oleic acid & D7 & 5280450 & -5.6 & Asp373 & Val664,Ile648,Asn647 \\
\hline & & & & & Met426,Gln377,Phe350 \\
\hline & & & & & Ile376,Lys 347,Asp649 \\
\hline & & & & & Asp467 \\
\hline \multirow[t]{4}{*}{ Stearic acid } & D8 & 5281 & -6.3 & Lys396,Leu393 & Pro397,Pro398,Lys 478 \\
\hline & & & & & Arg608,Ile667,Pro666 \\
\hline & & & & & His 665, Val664,Gln 402 \\
\hline & & & & & Asn660,Leu 394 \\
\hline \multirow[t]{4}{*}{ Palmitic acid } & D9 & 985 & -5.0 & Asp395,Lys396,Leu 393 & Pro397,Pro398,Val664 \\
\hline & & & & & Glu 552,His 553,Ser549 \\
\hline & & & & & $\mathrm{G} \ln 548, \mathrm{G} \ln 662, \mathrm{G} \ln 402$ \\
\hline & & & & & Leu394,Asn 660 \\
\hline \multirow[t]{4}{*}{ Z-4-Nonadecen-1-ol acetate } & D10 & 5363395 & -6.3 & Asn660,Lys396 & Leu393,Pro397,Pro398 \\
\hline & & & & & Gln402,Arg608,Lys 478 \\
\hline & & & & & Ile667,Ser473,Asn 421 \\
\hline & & & & & Tyr419,Pro666,Val664 \\
\hline \multirow[t]{4}{*}{ Methyl stearolate } & D11 & 534587 & -5.2 & $\mathrm{~N} / \mathrm{A}$ & Phe350,Lys347,Ile376 \\
\hline & & & & & Asp373,Gln 377,Met426 \\
\hline & & & & & Asp424,Gln 430,Asp467 \\
\hline & & & & & Asp649 \\
\hline
\end{tabular}

Ala34 
5280450

$-4.8$

Lys152,Asn 155

Ser154,Glu71,Leu55

Arg67,Leu 171,Ala172

Lys53,Asp168,Tyr35

\begin{tabular}{|c|c|c|c|c|c|c|}
\hline RELA (PDB ID: 2O61) & 3-[4-Methoxyphenyl]quinolin-4-ol & F1 & 279953 & -8.2 & Arg246 & Gln247,Phe307,Lys218 \\
\hline & Nonylamine & F2 & 16215 & -4.0 & Arg246 & Lys218,Arg305,Phe307 \\
\hline & & & & & & Val248,Gln 247 \\
\hline \multirow[t]{12}{*}{ PLA2G4A (PDB ID:1BCI) } & Lin oleic acid & G1 & 5280450 & -3.7 & Asp99 & Tyr96,Asn95,Phe63 \\
\hline & & & & & & His 62,Ala94,Arg61 \\
\hline & & & & & & Val97,Met98 \\
\hline & Oleic Acid & G2 & 445639 & -3.3 & $\mathrm{~N} / \mathrm{A}$ & Pro54,Thr53,Phe77 \\
\hline & & & & & & Lys 58,Leu 79,Glu 76 \\
\hline & & & & & & Ile78,Tyr16 \\
\hline & Erucic acid & G3 & 5281116 & -4.6 & $\mathrm{~N} / \mathrm{A}$ & Lys58,Leu79,Thr53 \\
\hline & & & & & & Tyr16,Ile78,Glu 76 \\
\hline & & & & & & Phe77 \\
\hline & Stearic acid & G4 & 5281 & -4.5 & Thr52,Asp80 & Pro54,Tyr16,Ile78 \\
\hline & & & & & & Leu 79 \\
\hline & Palmitic acid & G5 & 985 & -3.6 & Thr53,Lys 58,Asp55 & Pro54,Tyr16,Ile78 \\
\hline
\end{tabular}

Table 6. Comparative MDT between the best docking ligands in GL and positive controls. 


\begin{tabular}{|c|c|c|c|c|c|c|c|c|}
\hline \multirow[b]{2}{*}{ Compounds } & \multirow[b]{2}{*}{ PubChem ID } & \multirow[b]{2}{*}{$\begin{array}{l}\text { HSPB1 } \\
\text { (PDB ID:4MJH) }\end{array}$} & \multirow[b]{2}{*}{$\begin{array}{l}\text { PDGFRB } \\
\text { (PDB ID:3MJG) }\end{array}$} & \multicolumn{2}{|c|}{ Docking Score (kcal/mol) } & \multirow[b]{2}{*}{$\begin{array}{l}\text { MAPK14 } \\
\text { (PDB ID:1WBW) }\end{array}$} & \multirow[b]{2}{*}{$\begin{array}{l}\text { RELA } \\
\text { (PDB ID:2061) }\end{array}$} & \multirow[b]{2}{*}{$\begin{array}{l}\text { PLA2G4A } \\
\text { (PDB ID:1BCI) }\end{array}$} \\
\hline & & & & $\begin{array}{l}\text { PRKCB } \\
\text { (PDB ID:2I0E) }\end{array}$ & $\begin{array}{l}\text { PRKCA } \\
\text { (PDB ID:3IW4) }\end{array}$ & & & \\
\hline Benzamide, 4-acetyl-N-(2,6-dimethylphenyl)- & 147129 & -8.8 & 0 & 0 & 0 & 0 & 0 & 0 \\
\hline 1) HSP27 inhibitor J2 & 135384973 & -7.3 & a & 0 & a & 0 & a & प \\
\hline 3-[4-Methoxyphenyl]quinolin-4-ol & 279953 & 口 & -8.2 & 0 & 0 & 0 & 0 & a \\
\hline 2) Axitinib & 6450551 & प & -8.1 & 0 & 口 & 0 & a & प \\
\hline 1,2,3,4-Tetrahydro-9-methyl-6-cyclohexyl-1-carbazolone & 147129 & 0 & 0 & -8.4 & 0 & 0 & 0 & 0 \\
\hline 3) GO 6983 & 5280335 & 口 & 0 & -7.5 & 口 & 口 & a & a \\
\hline Benzamide, 4-acetyl-N-(2,6-dimethylphenyl)- & 535444 & 口 & 0 & प & -8.0 & a & a & a \\
\hline Benzamide, 4-acetyl-N-(2,6-dimethylphenyl)- & 147129 & a & 0 & 0 & 0 & -7.4 & 0 & 0 \\
\hline 5) JX-401 & 1126109 & $\square$ & $\square$ & $\square$ & $\square$ & -6.9 & $\square$ & $\square$ \\
\hline 3-[4-Methoxyphenyl]quinolin-4-ol & 279953 & a & 0 & 0 & प & 0 & -8.2 & व \\
\hline 6) Curcumenol & 167812 & a & 0 & 0 & 0 & 0 & -7.9 & 0 \\
\hline Erucic acid & 5281116 & 0 & 0 & 0 & 0 & 0 & 0 & -4.6 \\
\hline 7) Berberine & 2353 & a & 0 & प & 0 & a & a & -6.6 \\
\hline
\end{tabular}

1) HSPB1 inhibitor; 2) PDGFRB inhibitor; 3) PRKCB inhibitor; 4) PRKCA inhibitor; 5) MAPK14 inhibitor; 6) RELA inhibitor; 7) PLA2G4A inhibitor

Figures

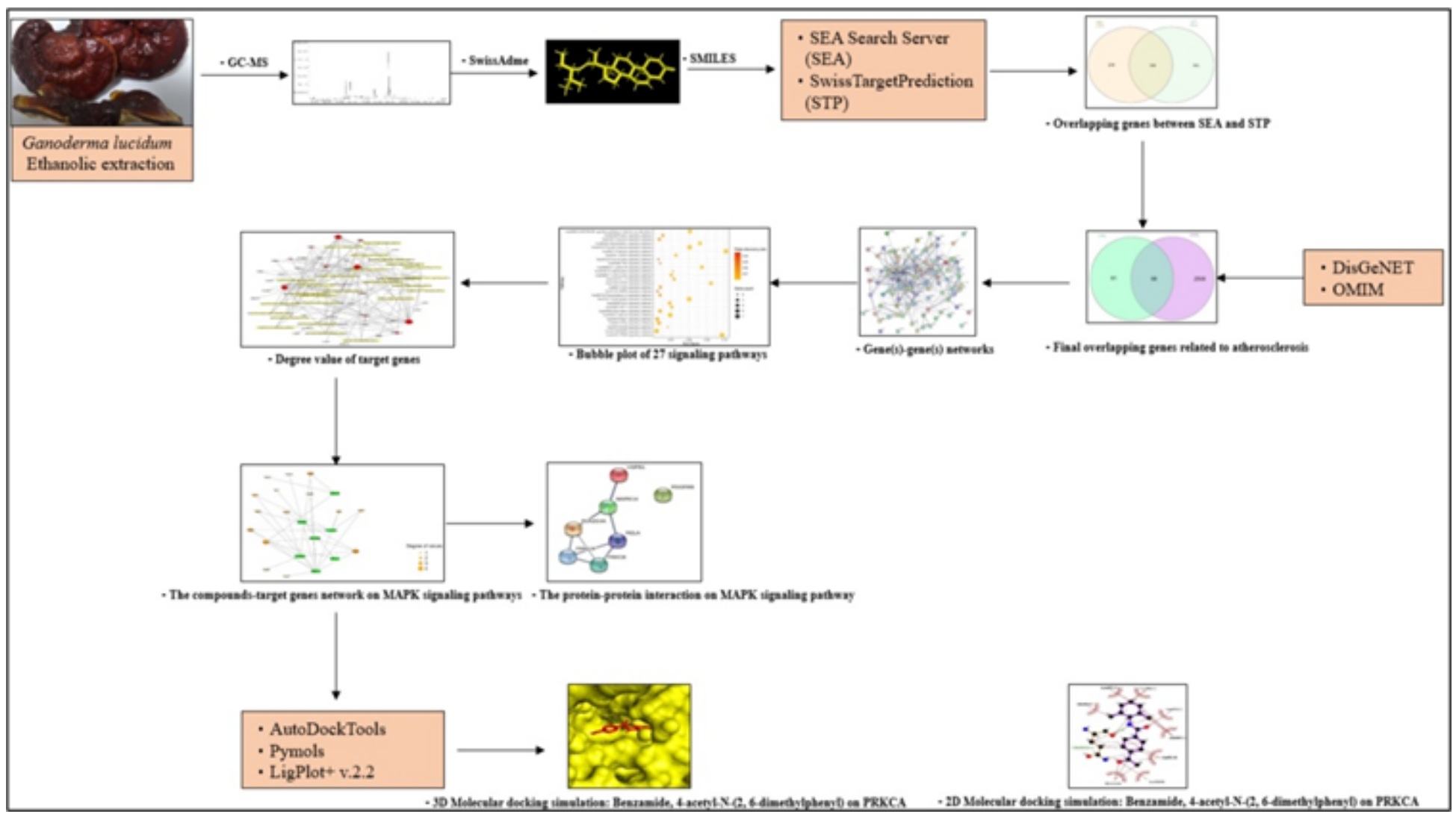

Figure 1 
The workflow schema of network pharmacology analysis for GL against AS.

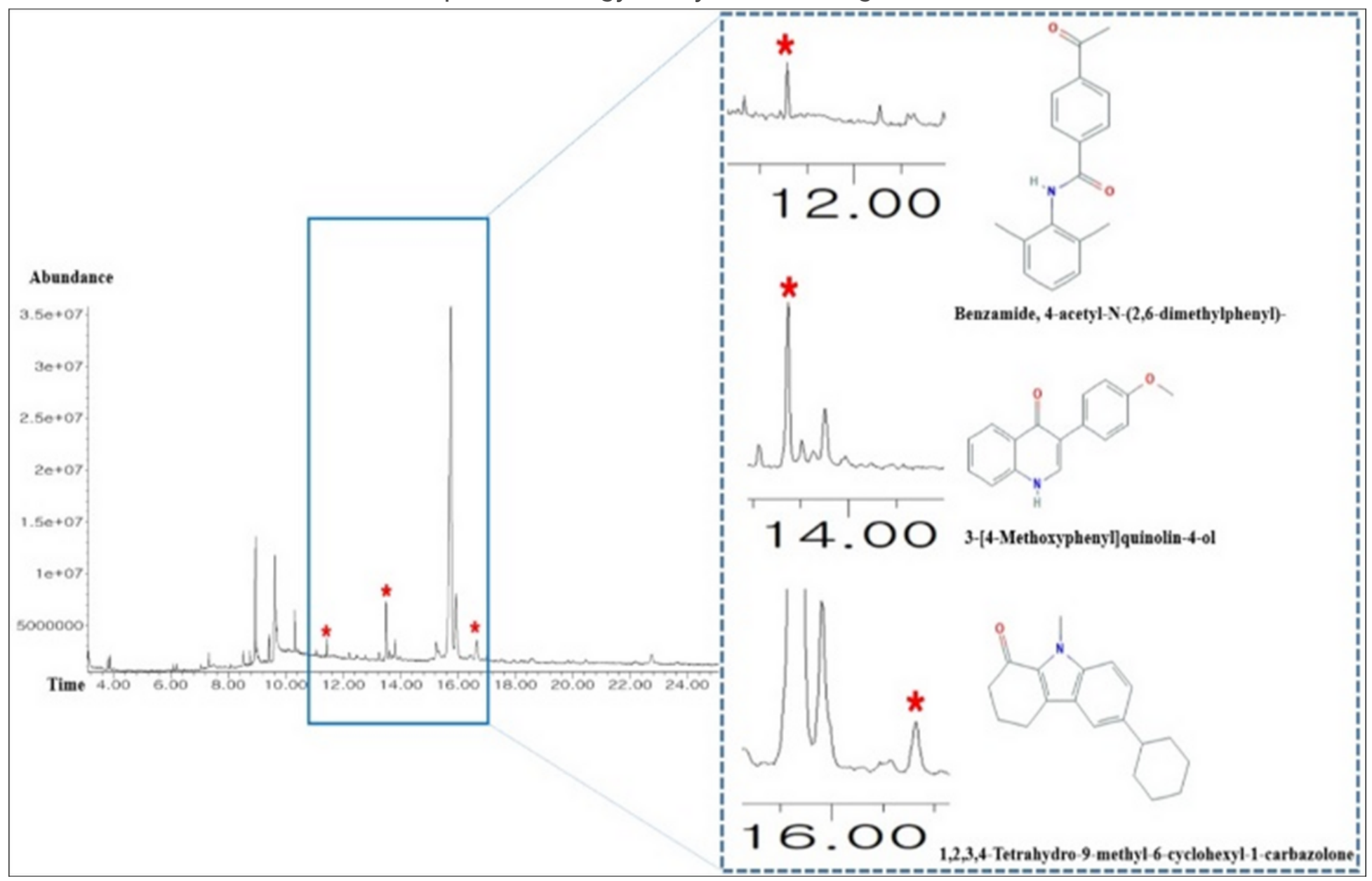

\section{Figure 2}

A typical GC-MS chromatogram of the chemical compounds of ethanolic extract of GL with 3 main chemical compounds. 


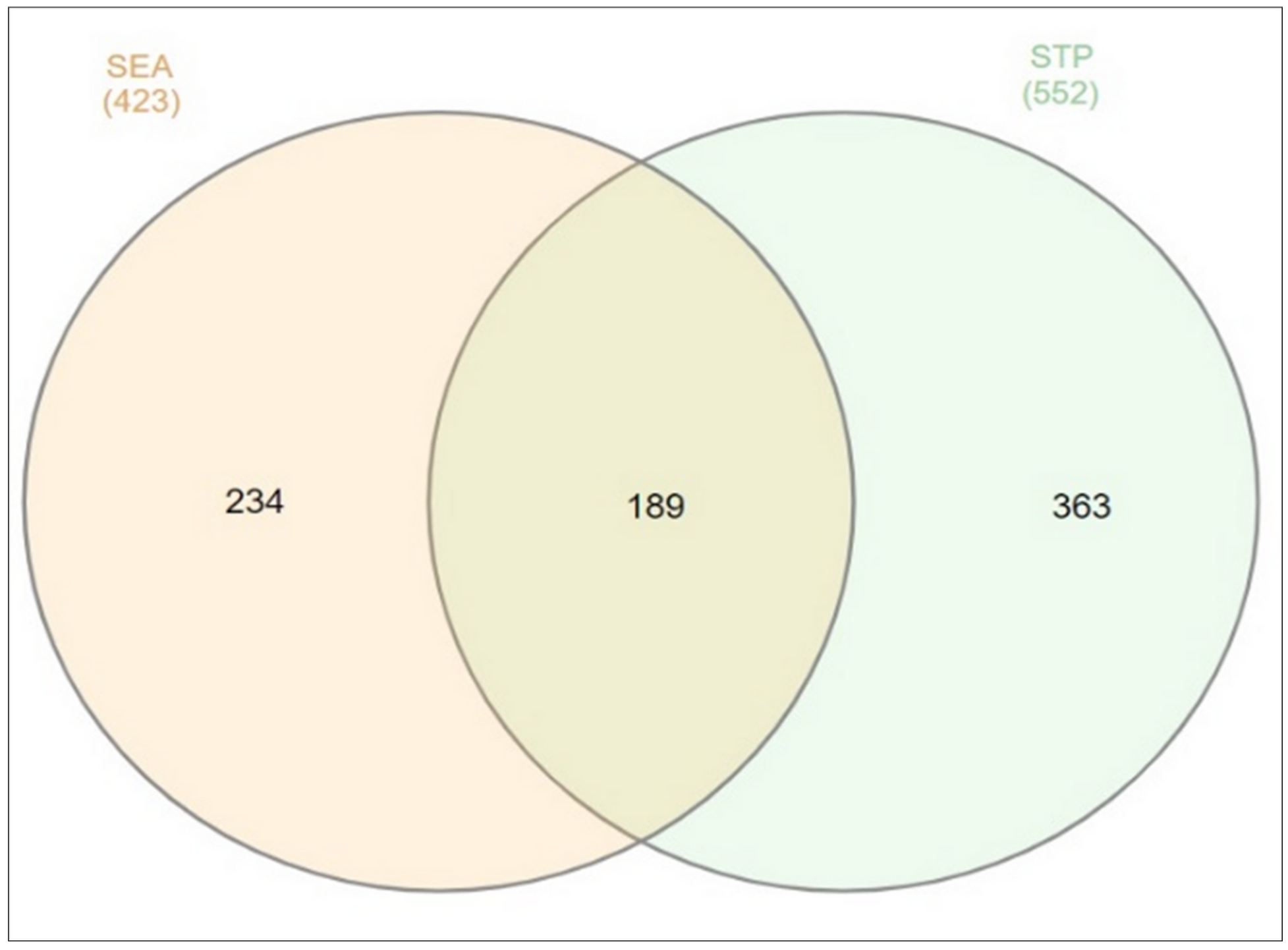

Figure 3

Overlapping genes (189 genes) between SEA (423 genes) and STP (552 genes).

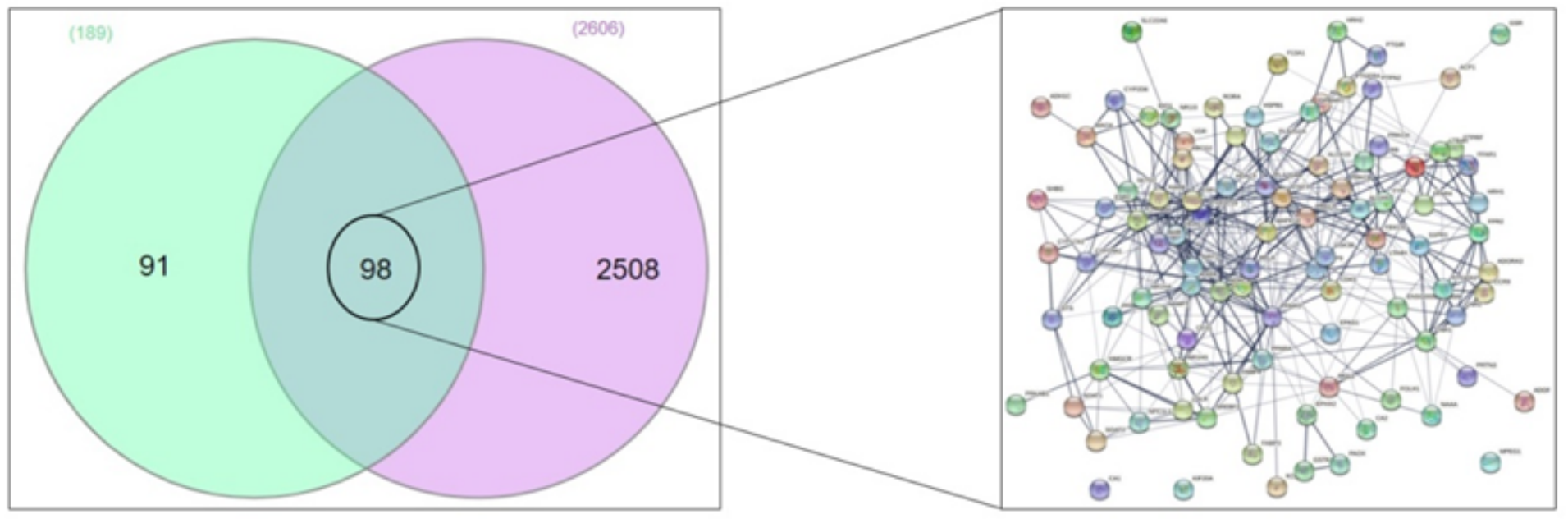

\section{Figure 4}


(A) Overlapping genes between 189 overlapping genes and AS-related genes (2,606 genes). (B) Genegene interaction of final overlapping 81 genes (98 nodes and 134 edges) in GL against AS.

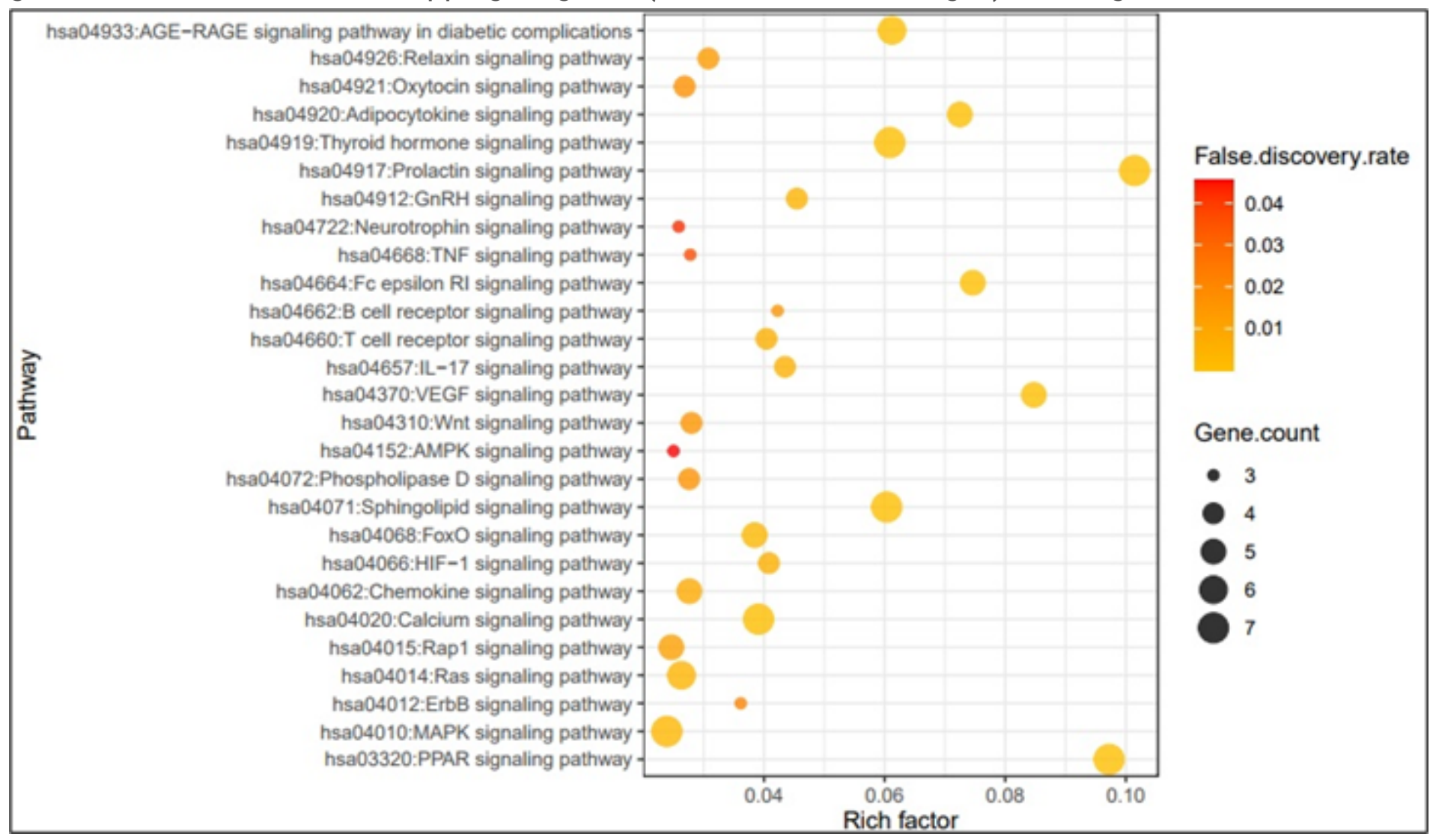

\section{Figure 5}

Bubble chart of 27 signaling pathways linked to the occurrence and development of AS. 


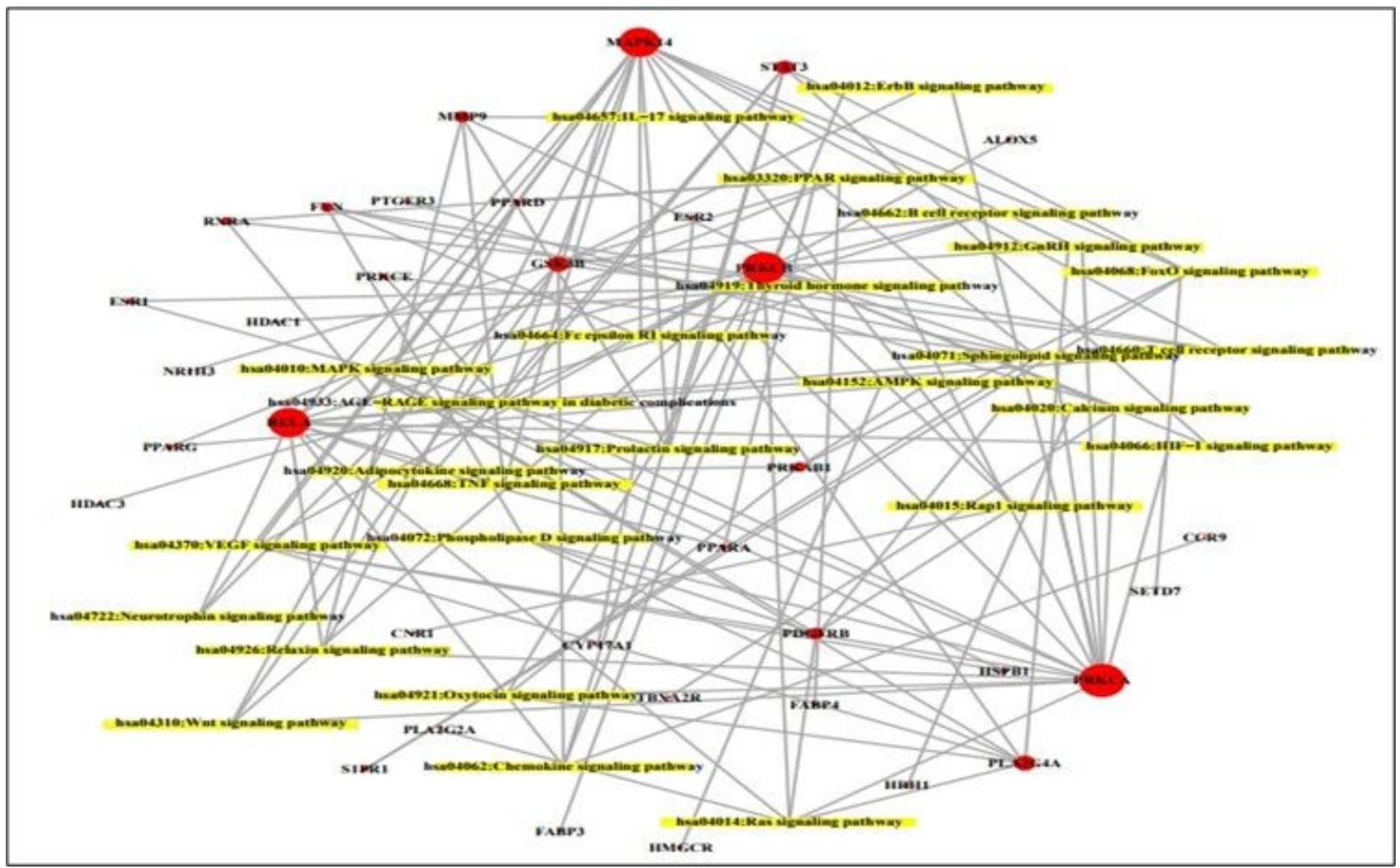

\section{Figure 6}

Interactive size map of 27 signaling pathways - core 34 targets. 
(A)

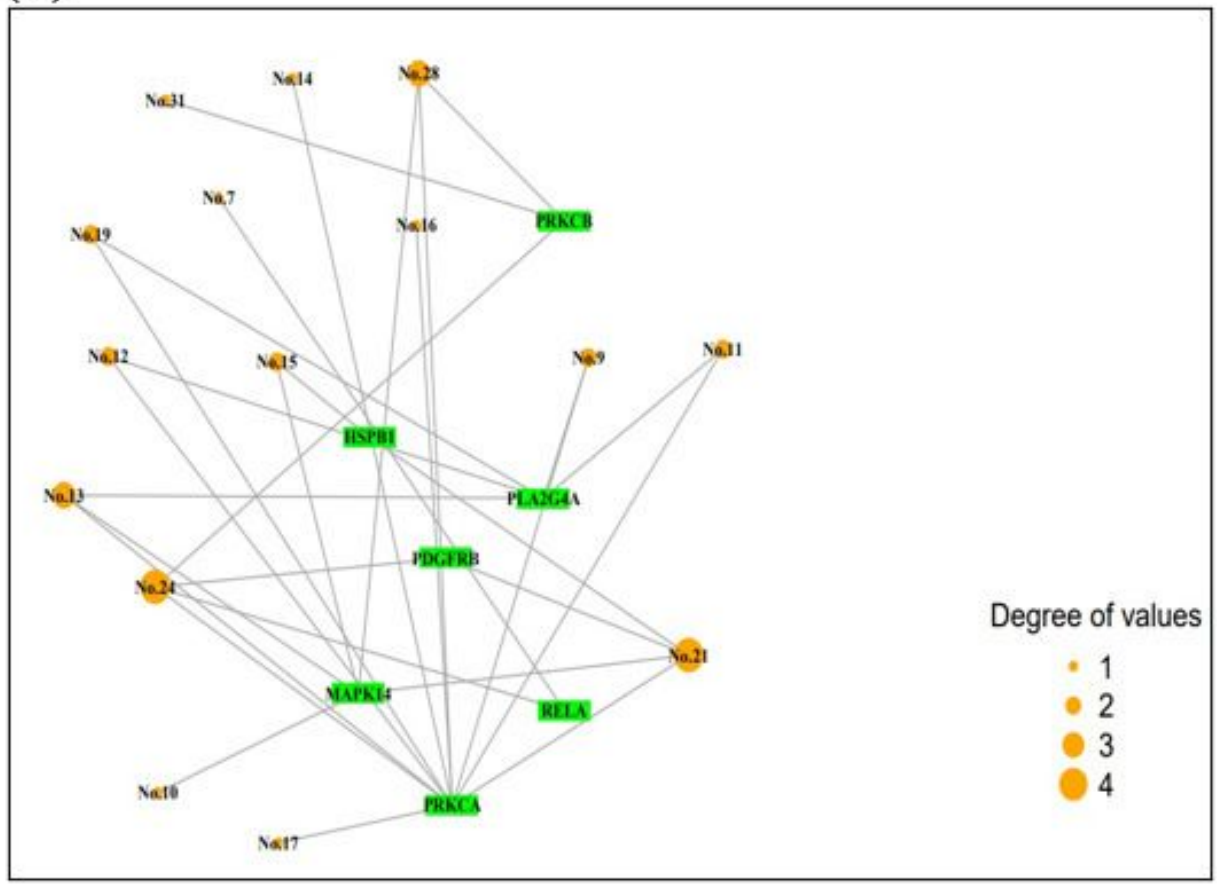

(B)

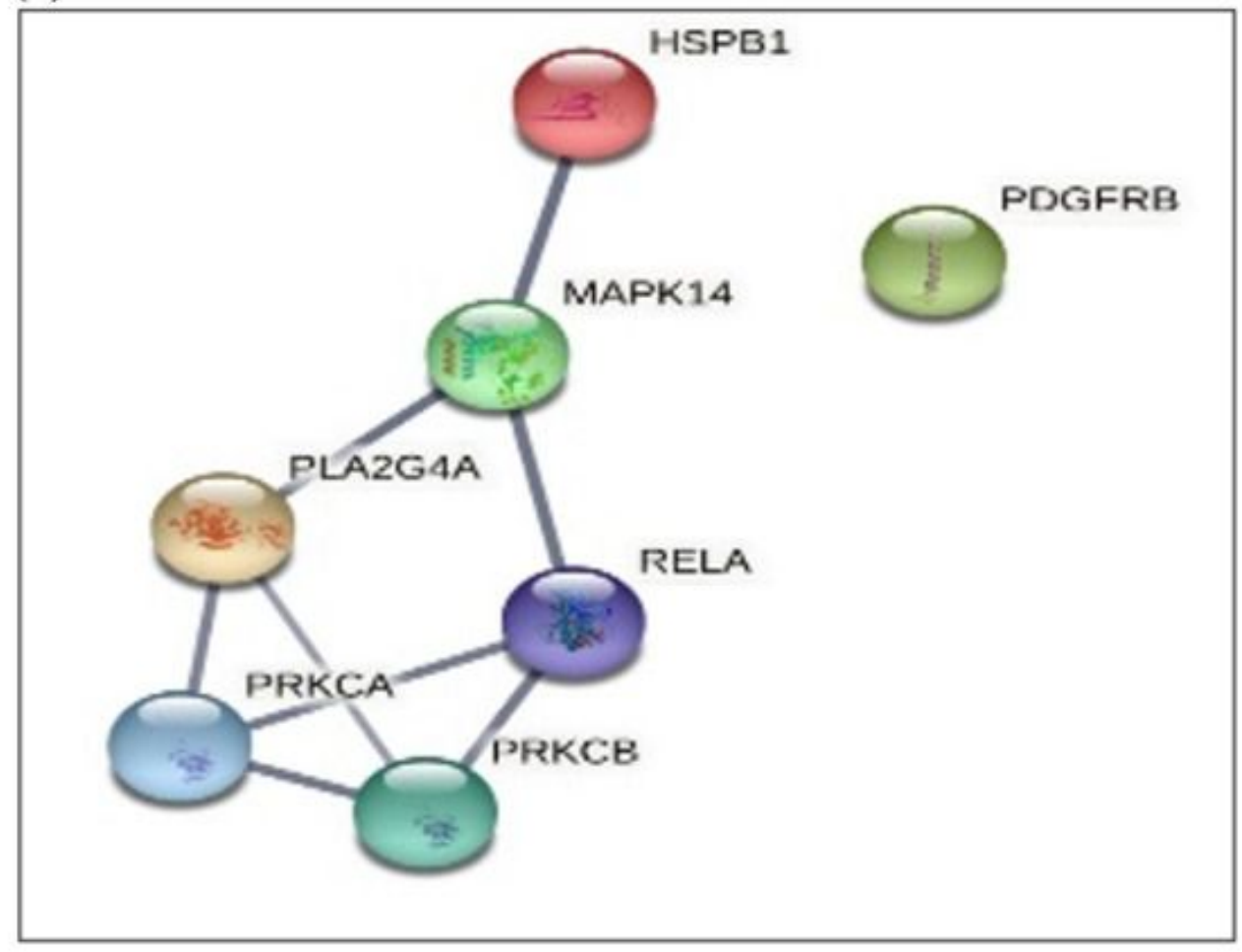

Figure 7

(A) Size map of compounds-target genes on MAPK signaling pathways (No.: the compound number of Table 1). (B) The protein-protein interaction on MAPK signaling pathway. 

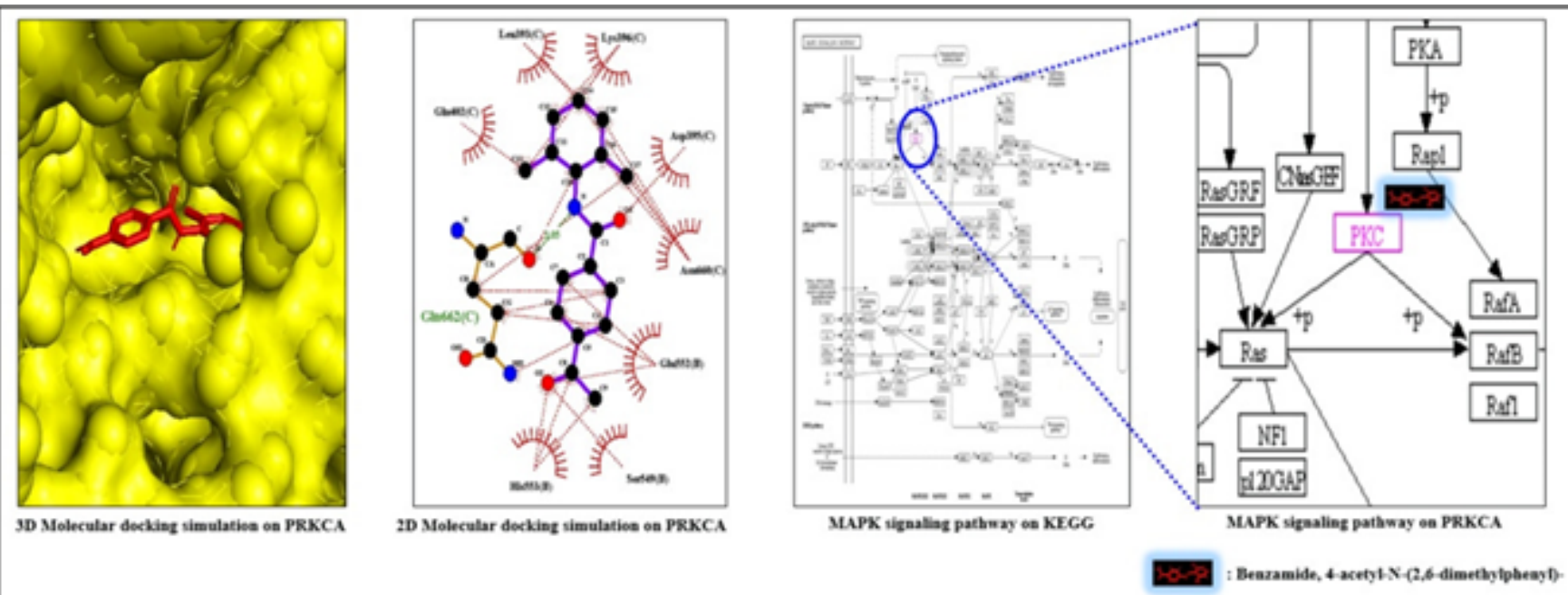

\section{Figure 8}

KEGG pathway diagram on MAPK signaling pathway and molecular docking interaction of Benzamide, 4acetyl-N-(2, 6-dimethylphenyl)- on PRKCA (PubChem ID: 3IW4)

\section{Supplementary Files}

This is a list of supplementary files associated with this preprint. Click to download.

- SupplementaryTables1.pdf

- SupplementaryTables2.pdf

- SupplementaryTableS3.pdf 